NBER WORKING PAPER SERIES

\title{
ELECTORAL VIOLENCE AND SUPPLY CHAIN DISRUPTIONS IN KENYA'S FLORICULTURE INDUSTRY
}

\author{
Christopher Ksoll \\ Rocco Macchiavello \\ Ameet Morjaria \\ Working Paper 29297 \\ http://www.nber.org/papers/w29297
}

\author{
NATIONAL BUREAU OF ECONOMIC RESEARCH \\ 1050 Massachusetts Avenue \\ Cambridge, MA 02138 \\ September 2021
}

This paper supersedes two earlier versions under the titles "Guns and Roses: Flower Exports and Electoral Violence in Kenya" and "The Effect of Ethnic Violence on an Export-Oriented Industry". We thank Oriana Bandiera, Tim Besley, Chris Blattman, Robin Burgess, Stefan Dercon, Oeindrila Dube, Marcel Fafchamps, Ray Fisman, Maitreesh Ghatak, Asim Khwaja, Eliana LaFerrara, Adrienne LeBas, Guy Michaels, Torsten Persson, Fabian Waldinger, Chris Woodruff and seminar and conference participants at CalTech, CSAE Oxford, GWU Africa Political Economy 2016, Kellogg MEDS, LSE, Manchester, Mannheim, NEUDC Tufts, NOVAfrica Conference 2016, Oxford, Political Economy Chicago Area 2016, IEA 2017 Mexico, ASSA Chicago 2017, John Hopkins Carey, and Simon Fraser for helpful comments and suggestions. For excellent research assistance we thank Ethan Nourbash, Ritwika Sen, Philip Spencer, Monica Toledo, and Timea Viragh. Morjaria thanks LSE-STICERD and NSF-IGCAERC for a travel award and EDRI Ethiopia for their hospitality. We gratefully acknowledge funding from iiG as part of the UK Department for International Development (DFID), George Webb Medley/Oxford Economic Papers Fund, Ford Motor Company Center for Global Citizenship and Global Poverty Research Lab at Kellogg School of Management. The views expressed herein are those of the authors and do not necessarily reflect the views of the National Bureau of Economic Research.

NBER working papers are circulated for discussion and comment purposes. They have not been peer-reviewed or been subject to the review by the NBER Board of Directors that accompanies official NBER publications.

(C) 2021 by Christopher Ksoll, Rocco Macchiavello, and Ameet Morjaria. All rights reserved. Short sections of text, not to exceed two paragraphs, may be quoted without explicit permission provided that full credit, including (C) notice, is given to the source. 
Electoral Violence and Supply Chain Disruptions in Kenya's Floriculture Industry

Christopher Ksoll, Rocco Macchiavello, and Ameet Morjaria

NBER Working Paper No. 29297

September 2021

JEL No. D22,D74,F14,O13,Q13

\begin{abstract}
Violent conflicts, particularly at election times in Africa, are a common cause of instability and economic disruption. This paper studies how firms react to electoral violence using the case of Kenyan flower exporters during the 2008 post-election violence as an example. The violence induced a large negative supply shock that reduced exports primarily through workers' absence and had heterogeneous effects: larger firms and those with direct contractual relationships in export markets suffered smaller production and losses of workers. On the demand side, global buyers were not able to shift sourcing to Kenyan exporters located in areas not directly affected by the violence nor to neighboring Ethiopian suppliers. Consistent with difficulties in insuring against supply-chain risk disruptions caused by electoral violence, firms in direct contractual relationships ramp up shipments just before the subsequent 2013 presidential election to mitigate risk.

Christopher Ksoll

Natural Resources Institute

Medway Campus, Central Avenue

Chatham Maritime, Kent

ME4 4TB

United Kingdom

c.j.ksoll@gre.ac.uk

Rocco Macchiavello

Management Department

London School of Economics \&

Political Science

London

United Kingdom

and CEPR

R.Macchiavello@1se.ac.uk

Ameet Morjaria

Kellogg School of Management

Northwestern University

2211 Campus Drive

Evanston, IL 60208

and NBER

a.morjaria@kellogg.northwestern.edu
\end{abstract}

A data appendix is available at http://www.nber.org/data-appendix/w29297 


\section{Introduction}

In many countries, political instability is a potentially major hindrance to firm performance. In the African context, violent conflicts, particularly at election times, are a common cause of instability and disruption (see, Bates, 2001, 2008). During the period from 1990 to 2018, $23 \%$ of the 348 elections which took place in Sub-Saharan Africa witnessed post-electoral violence (see Figure [1]).

Cross-country studies (see, e.g., Alesina et al., 1996, Collier, 2007; Glick and Taylor, 2010) show that violent conflicts have negative effects on growth, investment, and trade at the macro level. Micro-level evidence on the impact of violence on economic activity through firms' operations - necessary to understand the underlying mechanisms and formulate appropriate policies - remains limited. There are two major empirical challenges to providing micro-level evidence: (i) gathering detailed information on the operations of firms before, during, and after the conflict, and (ii) constructing a valid counterfactual - assessing what would have happened in the absence of the violence.

This paper investigates the mechanisms and costs of disruptions induced by the postelectoral violence in 2008 on the Kenyan floriculture industry. Export development is important to promote growth and poverty reduction in low income countries (see, e.g., Rodrik, 2005). The Kenyan floriculture industry provides an important example: one of the largest earners of foreign currency, the industry is also a major employer of lower educated women in rural areas. Besides its intrinsic relevance, the setting allows us to overcome the empirical challenges identified above. Kenyan flowers are produced almost exclusively for the export market. Since flowers are perishable, daily data on exports, available from trade transaction records at the firm level before, during, and after the violence, match day-by-day production activity on the farms. Moreover, flowers are grown and exported by vertically integrated firms and, therefore, the export data can also be matched with the exact location where 
flowers are produced 1 The ethnic violence that followed the elections in Kenya at the end of 2007 did not equally affect all regions of the country where flower firms are located. The detailed information on the time and location of production, therefore, can be combined with spatial and temporal variation in the incidence of the violence to construct several appropriate counterfactuals to assess the causal impact of the violence on production. We also designed and conducted a survey of flower firms in Kenya shortly after the end of the violence. The survey collected information on how firms were affected by and reacted to the violence. Once combined with the administrative data, the survey sheds light on the mechanisms through which the violence affected the firms.

Our core finding is that the electoral violence induced a large, negative, supply shock in the industry. Controlling for firm-specific seasonality and growth patterns, weekly export volumes of firms in the affected regions dropped, on average, by $56 \%$ relative to what would have happened had the violence not occurred. With regards to mechanisms, we show two sets of results. First, we find that workers' absence, which across firms averaged $50 \%$ of the labor force at the peak of the violence, was an important channel through which the violence affected production. Second, we explore heterogeneity in both firms' exposure and response to the violence. Firms with stable contractual relationships in export markets registered smaller proportional losses in production and reported proportionally fewer workers absent during the time of the violence. Rather than being less exposed to the violence, we argue that these exporters had stronger incentives to maintain production to preserve valuable reputation in export markets and, accordingly, exerted more effort to retain workers. These results hold even after controlling for characteristics of the labor force (gender, ethnicity), working arrangements (housing programs on the farm, farm certifications) and

\footnotetext{
${ }^{1}$ Other perishable agricultural products, instead, are grown in rural areas and then processed and exported by firms located in the larger cities of Nairobi and Mombasa. This precludes matching production with location. For other sectors - most manufacturing - that are not primarily involved in exports, accurate high-frequency data on production or sales do not exist.
} 
ownership (foreign, politically connected). After accounting for these characteristics, we find no evidence that foreign-owned firms, politically connected firms, or certified firms suffered differential reductions in exports and worker absence.

Given the large negative supply shock, it is important to understand how the demand side of the market reacted to it. We document that, at the time of the violence, global buyers sourcing through direct relationships were not able to shift sourcing of flowers to Kenyan suppliers in unaffected locations nor to suppliers in neighboring Ethiopia. Buyers' difficulties in finding alternative sources of supply are consistent with exporters' efforts to maintain deliveries. They also suggest that supply-chain risks induced by electoral violence are hard to insure against. Consistent with this hypothesis, exporters and buyers in direct contractual relationships mitigated the risk of supply-chain disruptions ahead of the subsequent 2013 presidential election by ramping up shipments just before the election.

This work contributes firm-level evidence on the impact of conflict on trade and firms, on the mechanisms that underpin its impact, and on the emerging literature on supply-chain disruptions $2^{2}$ The literature on the impact of conflict on trade has largely studied disruptions at a more aggregate level (see, e.g., Collier and Hoeffler (1998), Besley and Persson (2008), Martin et al. (2008), Glick and Taylor (2010).) More recently, Korovkin and Makarin (2019) estimates the effects of conflict on trade in non-conflict areas at the micro level using customs records between Russia and Ukraine. Our paper documents the effect of conflict on directly affected firms and the underlying mechanisms.

Recent contributions have greatly expanded our understanding of how conflict affects firms' performance. Conflict may affect firm performance through supply-side shocks such as distortions in markets for material and labor inputs Amodio and Di Maio, 2017; Klapper et al., 2013; Collier and Duponchel, 2013), unreliable transport, or the fear of theft; demand

\footnotetext{
2 Dercon and Gutiérrez-Romero (2012) and Dupas and Robinson (2012) provide survey-based evidence of the violence that followed the Kenyan presidential elections. The large literature on conflict is surveyed in Blattman and Miguel (2010).
} 
shocks from negative income effects (Montoya, 2016; Rozo, 2018); or effects at the extensive margin which influence firms' entry, exit, and location choices (Blumenstock et al., 2018). Hjort (2014) also studies the Kenyan flower industry in the aftermath of the 2008 presidential elections, although he focuses on the operations of an individual flower farm (whereas we provide sector-wide firm-level evidence), and the effects of conflict on firm performance through the channel of ethnic divisions within a firm 3 Our paper contributes to the literature by characterizing both the supply-side and demand-side responses to a short-lived, but intense, episode of violence. Our evidence also suggests that the business arrangements developed by firms to participate in global value chains are important in determining the impact of conflict on trade $4^{4}$

Finally, the paper contributes to the emerging literature on supply-chain disruptions. For example, Carvalho et al. (2021) exploit the Great East Japan Earthquake of 2011 to quantify the role of input-output linkages as a mechanism for the propagation of shocks. Barrot and Sauvagnat (2016) also study the extent to which firm-level shocks induced by natural disasters propagate in production networks and find particularly large effects for inputs that require specific investments. Blouin and Macchiavello (2019) show that the risk of delivery failures increases at times of sudden price spikes due to moral hazard. Finally, Macchiavello and Morjaria (2015) study relational contracts between exporters and global buyers in the Kenyan floriculture industry $5^{5}$ They exploit the same episode of electoral

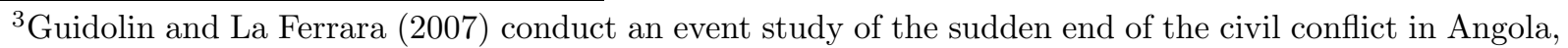
which was marked by the death of the rebel movement leader in 2002. They find that the stock market perceived this event as "bad news" for the diamond companies holding concessions there. In contrast to stock market reactions, our data allow us to unpack the various channels through which the violence has affected firms' operations.

${ }^{4} \mathrm{~A}$ complementary strand of the literature studies the impact of trade on conflict. For example, Dube and Vargas (2013) find that an increase in the international price of a labor-intensive (capital intensive) export commodity reduces (increases) violence in Colombia. Amodio et al. (2017) show that the imposition of trade restrictions contributes to conflict by inducing a deterioration in manufacturing and local labor market outcomes. We find suggestive evidence that, at the time of the violence, stable contractual relationships in export markets might have provided incentives to limit the impact of the violence.

${ }^{5}$ See also Antić et al. (2021) on contractual relationships and export strategies in the Ethiopian flower industry.
} 
violence to distinguish across competing models of relational contracting. The two papers are notably different. Unlike this paper, they focus on within-exporters differences in behaviour across relationships and treat the electoral violence as a reduced form of shock. In contrast, this paper documents the mechanisms through which the violence was a supply shock and explores across-firms heterogeneity in the incidence of, and response to, the violence. Using novel data, this paper also discusses the extent to which global buyers responded by shifting sourcing across regions in Kenya and, across the border to Ethiopia, and by adjusting ahead of the subsequent presidential election.

The remainder of the paper is organized as follows. Section 2 provides background information on the Kenyan flower industry and the post-electoral violence and describes the data. Section 3 presents the estimation strategy and empirical results. Section 4 discusses policy implications of our findings and offers concluding remarks. A theoretical framework, additional empirical results and details about the data are provided in an Appendix.

\section{Background and Data}

\subsection{Kenyan Flower Industry}

In the the last two decades Kenya has become one of the leading exporters of flowers in the world. Between 2005 and 2015 Kenya's share of the global floriculture increased from $5 \%$ to $11 \%$ with the country overtaking traditional producers such as Israel and Ecuador. Exports of cut flowers are among the largest sources of foreign currency for Kenya alongside tourism and remittances. The Kenyan flower industry counts around 100 established exporters located in various clusters in the country.

Coordination along the supply chain is critical to ensure the supply of high-quality, fragile and perishable flowers to distant markets. Flowers are handpicked in the field, kept 
in cool storage rooms at constant temperature for grading, then packed, transported to the airport in refrigerated trucks, inspected, and sent to overseas markets. The industry is labor intensive and employs mostly women in rural areas. The perishable nature of the flowers implies that post-harvest care is a key determinant of quality. Workers, therefore, receive significant training in harvesting, handling, grading, and packing, acquiring skills that are difficult to replace in the short run. Because of both demand (e.g., particular dates such as Valentines' Day and Mother's Day) and supply factors (it is costly to produce flowers in Europe during winter), floriculture is a business characterized by seasonality. Flowers are exported from Kenya either through the Dutch auctions located in the Netherlands, or through direct sales to wholesalers and/or specialist importers. In the first case, the firm has no control over the price and has no contractual obligations for delivery. In the latter, instead, the relationship between the exporter and the foreign buyer is governed through a (non-written) relational contract.

\subsection{Electoral Violence}

Kenya's fourth multiparty general elections were held on the December 27, 2007 and involved two main candidates: the incumbent Mwai Kibaki (a ethnic Kikuyu hailing from the Central province representing the Party of National Unity (PNU)) and Raila Odinga (a ethnic Luo from the Nyanza province representing the main opposition party, the Orange Democratic Movement (ODM)). The support bases for the two opposing coalitions were clearly marked along ethnic lines (see e.g. Gibson and Long, 2009).

Polls leading up to the elections showed that the race would be close. Little violence occurred on election day, and observers considered the voting process orderly. Exit polls gave a comfortable lead to the challenger, Odinga, by as much as $50 \%$ against $40 \%$ for Kibaki. The challenger led on the first day of counting (December 28) leading to an initial victory 
declaration by ODM (December 29). However, also on the $29^{\text {th }}$, the head of the Electoral Commission declared Kibaki the winner, by a margin of $2 \%$. The hasty inauguration of Kibaki on the afternoon of the December 30, resulted in Odinga accusing the government of fraud ${ }^{6}$ Within minutes of the election results announcement, a political and humanitarian crisis erupted nationwide. Targeted ethnic violence broke out in various parts of the country, especially in Nyanza, Mombasa, Nairobi and parts of the Rift Valley, where ODM supporters targeted Kikuyus who were living outside their traditional settlement areas of the Central province. This first outburst of violence, which lasted for a few days, was followed by a second outbreak of violence between January 25-30, 2008. This second phase of violence happened mainly in the areas of Nakuru, Naivasha, and Limuru as a revenge attack on members of ethnic groups perceived to be ODM supporters $7^{7}$ Sporadic violence and chaos continued until a power-sharing agreement was reached on February 29, 2008 (a calendar of events is provided in Appendix Figure [B1] which we use as a basis for defining the days of violence). By the end of the violence some 1,200 people had died in the clashes and at least 500,000 were displaced and living in internally displaced camps 8

\subsection{Data}

Firm-Level Data. Daily data on exports of flowers are available from trade transaction records for the period from September 2004 to June 2013. We restrict our sample to established exporters that export throughout the majority of the floriculture season. For most

\footnotetext{
${ }^{6}$ According to domestic and international observers the vote counting was flawed with severe discrepancies between the parliamentary and presidential votes (see, e.g., https://www.iri.org/ kenyas-2007-presidental-parliamentary-and-local-elections and https://www.foreign.senate. gov/imo/media/doc/MozerskyTestimony080207a.pdf)

'See, e.g. Kenya National Commission on Human Rights (2008), Independent Review Commission (2008), and Catholic Justice and Peace Commission (2008).

${ }^{8}$ The economic effects of the crisis were extensively covered in the international media. See, e.g., The International Herald Tribune (29/01/2008), Reuters (30/01/2008), China Daily (13/02/2008), MSNBC (12/02/2008), The Economist (07/02/2008, 04/09/2008), The Business Daily (21/08/2008), and The East African Standard (14/02/2008).
} 
of the analysis, we exclude traders as they account for a relatively tiny share of exports and we lack information on the location of farms where they source flowers. This leaves us with 118 flower-producing firms. The firms in our sample cover more than 90 percent of all exports of flowers from Kenya. We complement the Kenyan customs data with records from neighbouring Ethiopia for the 2007-2010 period.

To complement these records, we designed and conducted a survey of the industry. The survey was conducted in the summer following the violence through face-to-face interviews with the most senior person at the firm, which on most occasions was the owner. A sample of 75 firms, about three-fifths of established exporters, located in all the producing regions of the country, was surveyed (additional details on the data collection can be found in Appendix D). Further administrative information on location and ownership characteristics was collected for the entire sample of firms (see Table [1] $)^{9}$

Location and Days of Violence. We classify whether firms are located in areas that were affected by violence or not 10 The primary source of information used to classify whether a location suffered from violence or not is the Information Bulletin on the Electoral Violence Kenya Red Cross Society, 2008). These bulletins contain daily information on which areas suffered violence and what form the violence took (deaths, riots, burning of property, etc.). This information is supplemented by various sources (see Appendix D for details). The first spike of violence took place from the December 29, 2007 to January 4, 2008 while the second spike took place from January 25-30, 2008.

\footnotetext{
${ }^{9}$ We also gathered qualitative information on firms' behavior in preparation for the 2013 Kenyan presidential election through phone interviews with a few firms.

${ }^{10}$ In Appendix Table [C1] lists the flower-growing clusters according to industry reports in which firms are located. Appendix Figure [B2] shows the nearest towns where these firms are located within Kenya.
} 


\section{Evidence}

This section presents the empirical results. Section 3.1 summarizes the key predictions of the model in Appendix A. Section 3.2 discusses the identification strategy and presents the reduced form effects of the violence on production. Section 3.3 discusses a variety of

robustness checks and other outcomes. Section 3.4 introduces information from the survey to disentangle the main channels through which the violence affected the industry and considers heterogeneous effects for the firms during the violence. Finally, Section 3.5 considers the extent to which global buyers could react to the violence by shifting sourcing elsewhere and how the supply chain responded to increased risk ahead of the subsequent presidential election in 2013.

\subsection{Conceptual Framework}

The Appendix presents a theoretical framework to understand how firms were affected by, and reacted to, the violence. The model focuses on the aspects that are most salient to understand the particular episode we study and is not meant to portray a comprehensive treatment of how firms might be affected by violence. In particular, we take a short-run perspective in which a firm's capital and other input decisions are fixed, we assume an exogenous price for output not affected by the violence, and abstract from how the violence might increase uncertainty.

The framework delivers a set of testable predictions on the short-run effects of the violence on the firms:

1. Export volumes decrease due to the violence. Furthermore: (i) the likelihood of exporting on any given day also decreases because of the violence, but (ii) export volumes conditional on exporting might either increase or decrease as a consequence of the vio- 
lence depending on the relative importance of the reduction in the number of workers coming to work versus transportation problems.

2. The reduced form effect of the violence on production is greater for smaller firms and firms selling mainly through the Dutch auctions.

3. The mechanism works through the reduction in the number of workers coming to work. Smaller firms and firms selling mainly to the auctions, therefore, lose a higher proportion of their workers. Furthermore, if the proportion of workers who do not show up for work is directly controlled for, those firms do not suffer larger reductions in exports.

The model also offers guidance to calibrate the costs of the violence for the firms involved, as described below.

\subsection{Reduced Form Estimate of the Effect of Violence on Exports}

In this section we quantify the effects of the violence on firms' exports. The location and timing of the violence was driven by the interaction between political events at the national and local level and regional ethnic composition (see e.g. Gibson and Long, 2009). Therefore, the occurrence of violence in any location was not related to the presence of flower firms. In fact, intense violence was registered in many locations outside of our sample - i.e., in places without flower firms (e.g., slum areas in Nairobi and other major towns). In the baseline analysis, we condition on flower firms' locations and exploit the cross-sectional and temporal variation in the occurrence of violence between "violence" and "no-violence" regions. In some locations flower farms are relatively large employers. To eliminate concerns that a firm's response and behavior at the time of the crisis affected the intensity and/or duration of violence in its location, we take an "intention-to-treat" approach in which we classify 
locations as having suffered violence or not during a pre-specified time spell which is kept constant across locations involved during the same spike (see Appendix D for details on the exact dates and location of the violence).

Table 11 reports summary statistics for the industry in the two regions. Panel A reports data from administrative records, while Panel B focuses on information from the survey. Both panels show that firms in the regions affected by the violence are broadly similar to firms in regions not affected by the violence. It is important to stress that our identification strategy does not rely on the two groups of firms being similar along timeinvariant characteristics, since these are always controlled for by firm fixed effects. Finally, Panel $\mathrm{C}$ shows that the sample of surveyed firms is representative of the entire industry. Firms in the violence region, however, were over-sampled in the survey.

Table 2 investigates the short-run impact of the violence. To do so, it is necessary to control for season (or growth) and seasonality effects. Let $Y(i)_{T, W}^{L}$ be the exports of flowers by firm $i$ in location $L$ in period $T$ in winter $W$. The indicator $L$ takes a value of $L=1$ if the firm is in a location that is affected by the violence after the election and $L=0$ otherwise. The indicator $T$ takes a value of $T=1$ during the weeks in January and early February during which violence occurred and $T=0$ during our control period, which are the 10 weeks before the end of December. Finally, the indicator $W$ takes value equal to $W=1$ in the winter during which the violence occurred - i.e., the winter of 2007/8 and $W=0$ for the previous winter. With this notation, and following our "ITT" approach, a firm was affected during a particular spike of violence if and only if $V=L \times T \times W=1$.

Panel A focuses on the first spike of violence, while Panel B focuses on the second spike. The two panels, therefore, differ in their definition of the violence period $T=1$ (but not of the control period $T=0$ ). The two panels also differ in the division of firms across locations classified as being affected by the violence, i.e., L. In Panel A there are 20 firms affected by the violence, while in Panel B, 55 firms are located in regions affected by the 
second spike of violence. In both panels the sample includes 135 firms.

Under the assumption that the change in exports between $T=0$ and $T=1$ is constant across winters, it is possible to estimate the effects of the violence on production for each firm $i$ by looking at the following difference-in-difference:

$$
\widehat{\gamma}^{L}(i)=\underbrace{\left(Y_{T=1, W=1}^{L}-Y_{T=1, W=0}^{L}\right)}_{\Delta_{T=1}^{L}(i)}-\underbrace{\left(Y_{T=0, W=1}^{L}-Y_{T=0, W=0}^{L}\right)}_{\Delta_{T=0}^{L}(i)} .
$$

Intuitively, this means, e.g., that the worldwide demand for flowers for the time of January and February relative to the 10 weeks leading up to Christmas did not change across the two seasons. The first difference, $\Delta_{T=1}^{L}(i)$, compares exports during the time of the violence with exports at the same time in the previous winter. This simple difference, however, confounds the effects of the violence with a firm's growth rate across the two winters, which is of particular importance in a fast-growing sector. The second difference, $\Delta_{T=0}^{L}(i)$, estimates the firm's growth rate comparing the non-violence periods - the 10 weeks before Christmas - in the two winters. Under the assumption that the growth rate between two successive winters is the same for the weeks before Christmas and in January/February, the difference-in-difference $\widehat{\gamma}^{L}(i)$ provides an estimate of the effects of the violence which controls for a firm's growth rate. Appendix Table [C2] uses data from the two seasons preceding the violence to provide support for this identifying assumption. The table shows that seasonality patterns are constant across seasons and similar across regions ${ }^{11}$

The bottom rows in Panel A and Panel B of Table [2] report the average $\widehat{\gamma}(i)$ across firms for the two spikes of violence, with columns (A) and (B) presenting the results for the no-violence region and the violence regions, respectively. Panel A shows the impact on the 20 firms that were directly affected by the first spike of violence. Rows [3a] and [4] in column

\footnotetext{
${ }^{11}$ Later, we provide further support to the identification strategy by reporting parallel trends across regions. For intuition, the identification strategy is also provided graphically in Appendix Figure [B3].
} 
(B) show that estimated coefficients for the simple difference and the difference-in-difference estimates for the effects of the first spike of violence are -1.83 and -1.48 (which translate roughly to a $56 \%$ drop in exports). Panel B shows that the larger group of 55 firms that were directly affected by the second spike of violence suffered a smaller reduction in exports, a difference that is not statistically significantly different from zero.

The difference between rows [3a] and [4] in Panel A highlights why accounting for seasonality is so important: the simple difference overestimates the effect of violence on firms affected by conflict (as estimated by the difference in difference in row [4]) by -0.34, as it does not take into account the lower demand for flowers in the first few weeks of the year relative to the period before the election. This is also a possible explanation for the statistically significant simple difference within the no-violence region of -0.53 (which is also about -0.34 smaller than the estimated effect of this period in the no-violence region).

Panel B shows diverging experiences in the second spike of the violence. The differencein-difference point estimate in the violence region is negative, while it is positive in the towns not directly involved in the violence. Neither of the two coefficients is statistically significant at conventional levels. The positive point estimate for no-violence regions could arise if firms where trying to make up for losses during the first spike or if there were positive spillovers. Positive spillover could arise, e.g., if buyers who prior to the conflict sourced from violence areas might try to source from non-violence locations to satisfy their unmet demand and hence this could cause an increase in exports. Section 3.5 explores this scenario directly but finds no evidence for it.

Cross-Regional Comparison: Triple Differences. One limitation of the difference-indifference estimates is that they do not account for demand shocks that are specific to a date and winter. This would be the case, for example, if European demand were particularly high for roses for the 2007/2008 new year. A difference-in-differences approach would conflate 
such demand shocks with the supply shocks induced by the violence. Under the assumption that any change in the seasonality across winters is the same for the violence and no-violence areas (which also excludes cross-region spillovers), firms in regions not directly affected by the violence can also be used as a control group to estimate the direct effects of the violence and to account for such demand shocks. Defining by $\bar{\Delta}^{L}=\frac{1}{N_{C}} \Sigma_{i \in C} \widehat{\gamma}^{L}(i)$ the average of the difference-in-difference estimates for each firm in location $L$, a triple difference estimate of the direct impact of the violence is given by

$$
\Delta=\bar{\Delta}^{L=1}-\bar{\Delta}^{L=0}
$$

The triple difference estimates are presented in column (C) of row [4] in each of the two panels. For the first shock of violence, the triple difference is -1.30 , roughly in line with the difference-in-difference estimates. The triple difference estimate for the second spike of violence is roughly half in size, at -0.61 .

Conditional Regressions. Panel A in Table [3] estimates the impact of the violence on production using daily export data. The estimated regression is given by

$$
y_{i d}=\alpha_{i}+\mu^{m}+\eta^{d}+\lambda^{W}+\theta(\mathbf{W} \times \mathbf{T})+\gamma_{D D D}(\mathbf{W} \times \mathbf{T} \times \mathbf{L})_{i d}+\varepsilon_{i d}
$$

where $y_{i d}$ denotes exports of firm $i$ on a particular date (e.g., January 20, 2008). Location $L \in\{0,1\}$ and period $T \in\{0,1\}$ are defined as above while winter $W \in\{0,1\}$ is defined over all available years, i.e., with $W=0$ indicating the three winters pre-dating the violence and $W=1$ the winter of $2007 / 8$. Day of the week dummies (i.e., Monday, Tuesday...) are denoted by $m$. The specifications control for firm-specific effects $\alpha_{i}$; day of the year effect $\eta^{d}$; winter-specific effect $\lambda^{W}$ (where we allow a different $\lambda^{W}$ for each of the four winters); as 
well as day of the week effect $\mu^{m}$. Finally, $\varepsilon_{i d}$ is an error term ${ }^{12}$

The indicator functions $\mathbf{W}, \mathbf{T}$ and $\mathbf{L}$ take values equal to one in, respectively, the winter, period, and location in which the violence took place, and zero otherwise. Let us define being affected by violence as $V_{W T L}=\mathbf{W} \times \mathbf{T} \times \mathbf{L}$, and let $V_{W T}=\mathbf{W} \times \mathbf{T}$. The coefficient of interest is $\widehat{\gamma}_{D D D}$, which provides an estimate of whether, relative to the previous winters and accounting for seasonality, exports of firms in the violence-affected areas behaved differently from exports in the no-violence areas during the period of the violence. Columns in Table [3] include these covariates with progressively less restrictive assumptions.

Column (1) reports the triple difference estimate allowing for different intercepts for the day of the year, the particular day of the week, and the winter. Column (2) adds firm fixed effects. Column (3) allows for different winter fixed effects in the violence and no-violence areas (that is different growth across the violence and the no-violence regions between successive winters). As mentioned above, the floriculture trade is seasonal and the seasonality could be different across locations. Column (4) allows flexibility in the seasonal patterns across regions and is our primary specification. The coefficient of interest $\widehat{\gamma}_{D D D}$ for both the first and second outbursts of violence are very similar in magnitude to those estimated in Table [2].

Parallel Trends. The results in column (4) are illustrated by Figure 2]. The figure plots median residuals of the corresponding baseline regression for firms in the violence and in the no-violence regions, when the violence terms $V_{W T}$ and $V_{W T L}$ are not included in the specification. The figure supports the identification strategy: we do not find any evidence of

\footnotetext{
${ }^{12}$ With regards to statistical inference, there are two main concerns. First, production and, therefore, shipments of flowers of a given firm are likely to be correlated within each firm, even conditional on the fixed effect. If shipment to a particular buyer has occurred today, it is less likely that another shipment to the same buyer will occur tomorrow. Second, across firms, error terms are likely to be correlated because firms are geographically clustered and, therefore, shocks to, e.g., roads and transport, are correlated across neighboring firms. Throughout the analysis using custom records, therefore, standard errors are clustered both at the firm and the season-week-location level using the Cameron et al. (2011) procedure.
} 
differences in trends or behavior across regions in the weeks leading up to the violence.

Firm-Specific Growth and Seasonality. Finally, columns (5) and (6) allow for firmspecific seasonality patterns and firm-specific growth between winters and show that the estimates of the impact of the violence are robust to allowing flexible growth and seasonality patterns across firms. Due to the large number of fixed effects being estimated, the statistical significance is somewhat reduced in column (6).

As noted above, using the no-violence region as a control group could lead to estimates contaminated by spillover effects. Panel B of Table [3], therefore, repeats the same specifications as in Panel A focusing exclusively on the firms located in the violence regions. The resulting estimates are very similar to those in Panel A once the extensive set of covariates are used, suggesting that spillovers are of relatively small magnitude. Panel C provides more direct difference-in-difference evidence on a possible effect of the violence on the control locations. This first placebo test shows that there is no overall effect on the control areas, at least not compared with previous seasons and relative to the pre-election period, on average.

\subsection{Robustness checks}

We conduct additional robustness checks that assess possible alternative explanations of the observed patterns. Specifically, we (1) investigate the effect of moving away from using a binary categorization of locations into conflict and no-conflict areas, (2) assess whether infrequent exporters and traders exported additional flowers during this time, (3) investigate location-specific growth and seasonality, and (4) conduct a placebo analysis for the period prior to the conflict.

Violence Intensity and Localization. In Appendix Table [C3], we assess the robustness of the binary categorization of firms into violence versus no-violence areas by allowing for the 
intensity and the influence area of the conflict to vary. We use the Armed Conflict Location and Event Data Project (ACLED) as an alternative source of conflict data. This project geo-codes all instances of political violence and protest around the world and hence also covers episodes of election violence.

The table provides evidence on the effect of violence at different radii from the flower firm premises $(5 \mathrm{~km}, 10 \mathrm{~km}$ and $20 \mathrm{~km}$ ) and of the intensity of violence. Columns 1 to 9 show that the effect of violence is very localized. We find a statistically significant effect of any report of violence (or any report of fatal violence) in a $10 \mathrm{~km}$ radius, but not at a $20 \mathrm{~km}$ radius from the flower firms' premises.

Columns 10 to 12 consider a definition of the violence that takes into account the number of fatal accidents. We find no statistically significant relationship between the number of fatalities and the drop in export. We interpret this as evidence that rather than the violence itself, it is the associated disruptions and workers' worries due to the fear of violence and associated insecurity that leads to the drop in production.

Traders and Infrequent Exporters. One potential concern for our empirical strategy, which relies on using detailed information on established flower exporters to be able to match export activity to the location of the violence - is that it omits exports of firms who are not established exporters or for whom we do not have location information that would allow us to assign them into a violence or no-violence group. This is the case for flower traders, for which we do not have information on the location of the farms they source flowers from. Similarly, there are a few infrequent exporters for whom we have export records over the prior years, and there could have been exports by new entities during this period. Appendix Figure [B4] shows the total exports of these excluded exporters. Their overall exports are low, and we do not find any pattern of concern that would suggest that traders may have exported additional amounts of flowers during this period. 
Placebo and Further Tests. The empirical strategy that underlies much of our analysis relies on the assumption that there is nothing special about flower supply in the violence area during the time of the conflict that is not related to the violence. While we cannot test that assumption directly, we can assess whether exports of firms located in the violence area appear different just before the election. Appendix Table [C4] shows that there is no differential pattern in exports in the weeks leading up to the election violence.

To address concerns that there might be location-specific patterns of seasonality and growth, Appendix Table [C5] shows that the results are robust to accounting for locationspecific seasonality effects. Due to the large number of fixed effects, several of the results are less precisely measured, but the magnitude is very close to those in our main Table [2].

Effects on Other Firm Outcomes. Appendix Table [C6] presents results for other outcomes. Column (1) presents the estimate for daily export data and our baseline specification again as in column (4) of Table [3]. The negative effects on export volumes in a given day can be decomposed into two effects: a decrease in the likelihood of exporting, i.e., the extensive margin, (column (2)) and a decrease in the export volumes conditional on exporting, i.e., the intensive margins (column (3)).

Results indicate that the second outbreak of violence had a negative and significant impact on a firm's ability to export, while the negative point estimate is not significant for the first period of violence. During both episodes, the export volumes conditional on exporting decreased as a consequence of the violence, but not significantly so. An extension of the model delivers ambiguous predictions for the conditional export volumes, since flowers can, though not ideal, be harvested a day or two earlier or later. Column (4) shows that the unit value in Kenyan shillings (in logs) increased during both episodes of violence. This result, however, simply captures the substantial depreciation of the Kenyan currency during the violence. The Kenyan shilling went from a high of $90 \mathrm{KShs} /$ Euro prior to the presidential elections to 
an exchange rate of 100 KShs/Euro during the first outbreak and depreciated further to 108 KShs/Euro during the second outbreak of violence. Unreported results confirm that unit values in Euros did not change during the violence. Furthermore, these results confirm that there was no differential effect on unit values in Kenyan shilling across regions at the time of the violence.

Column (5) documents that there was no effect of the violence on unit weight either. In the case of roses, which represent the vast majority of flowers exported from Kenya, a key determinant of a flower's value is its size which is, in turn, determined by the altitude at which the firm is located. Firms are, therefore, relatively specialized in the size of flowers grown and the evidence confirms that the violence did not affect the composition of exports.

Medium-Run Effects. The violence dummies are defined for the short (i.e., five- to six-day) periods that correspond precisely to the two spikes of violence. For several reasons, however, it is interesting to consider a longer definition during which violence may have affected exports. First, sporadic violence occurred throughout the month of February 2008. While not directly affecting firms' operation, the violence could have created an uncertain business climate that may have had indirect effects on the industry. Second, (though none of our respondents mentioned this) firms might have tried to store flowers or intensify production in the days immediately following the violence in hope of recovering the losses. Finally, it is interesting to see whether the violence had medium-run effects on the firms (e.g., because of damage to a firm's assets, such as plants, due to workers' absence). Appendix Figure [B5] reports the cumulative and the medium run-effects of the violence throughout the month of February 2008. While the cumulative effect remains negative and shows that firms never recovered the losses in production incurred during the time of the violence, the figure also shows that in about one week to 10 days after the end of the second spike, firms were not suffering any significant medium-run effects of the violence. The relatively short delay 
in recovery is consistent with workers returning to their jobs shortly after the violence ended.

\subsection{The Violence as a Supply Shock: Mechanisms}

This section investigates the mechanisms through which the violence affected firms. First, using the survey, we corroborate the violence indicators used in the previous section: firms in locations classified as having suffered from the violence are more likely to report to have worker absence, experienced transportation problems and hired security. Second, we explore heterogeneity in the response to the violence. We then explore the role of workers' absence and transportation problems in affecting firms' performance during the violence. Finally, we attempt to quantify the short-run losses incurred by firms during the violence.

Incidence of the Violence: Survey Responses. Before turning to the evidence on production, Appendix Table [C7] shows that survey responses about the violence are very strongly correlated with the definition of the violence region that we have used in the reduced form specifications above. In particular, firms located in the violence regions are significantly more likely to report that their operations have been directly affected by the violence (column 1), there were days in which members of staff did not come to work because of the violence (column 2), the firm experienced a higher proportion of workers absence due to the violence (column 3), worker absence caused significant losses in production (column 4), the firm

experienced transportation problems in delivering flowers to the airport (column 5) and the firm hired extra security personnel during the violence period (column 6).

Heterogeneity in Workers and Export Losses. We now test the model's predictions exploring heterogeneity across firms. Table [4 reports cross-sectional correlations between the firms' characteristics and the percentage of workers absent at the peak of the crisis for firms in the violence location. While firms in the violence and no-violence regions appear to 
be broadly comparable along observable characteristics (see Table [1]), the same is not true across locations within the violence and no-violence regions. Since locations also differ in the intensity of the violence, the specification includes location dummies as controls.

Table [4, in particular shows a correlation between the marketing channels and (in most specifications) the size of the firm and the percentage of workers absent during the violence. In particular, among firms located in the regions affected by the violence, we find that firms exporting through the auctions and smaller firms report a higher fraction of workers missing during the violence period. The correlation between marketing channel and size is robust to the inclusion of a large number of covariates, including (i) location dummies to account for the intensity of the violence, (ii) dummies for housing, social programs, and fair-trade-related certifications, (iii) the gender composition of the labor force, (iv) owners' identity, (v) product variety, and (vi) proxies for capital invested in the firm.

The results could, in principle, be driven by systematic differences in the composition of the labor force across firms. For example, firms employing a higher percentage of the minority group in a given locality might suffer higher worker and export losses. In column (7) we include a measure of the proportion of the workforce that is at risk of violence. We define being at risk as being a member of an ethnic group that was in the opposite alliance from the majority ethnic group of the location. While this proportion at risk is positively correlated with a higher proportion of workers lost, the effect is not precisely estimated.

Table [5] reports the heterogeneity results in exports. We focus on the second outbreak of violence (as in Panel B of Table 2]) since the small number of firms affected during the first period of violence (20) precludes the estimation of heterogeneous effects. We include the firms' characteristics as in Table [4] interacted with the violence period dummy. For ease of exposition, the table only reports the coefficients on the interactions between the shock and the firms' characteristics of interest.

The evidence supports the predictions of the model with respect to firm size and 
marketing channels: on average, smaller firms and firms exporting through the auctions suffered a greater reduction in export volumes during the violence. ${ }^{13}$ The last column in the table shows that these correlations are robust to controlling for several other firms' characteristics. Similar to the results in Table [4, we find that the proportion of workers at risk is not significantly correlated with the size of the effect of the violence.

In sum, the results of the heterogeneity analysis appear to be broadly consistent with the predictions of the model. The results must, of course, be interpreted cautiously and, in particular, care should be taken before interpreting the estimates in Tables [4] and Table [5] as causal effects of firm size or marketing channel on exports and worker retention during the violence. Unobservable characteristics might correlate with a firm's exposure, or capacity to react, to the violence as well as with the firm's size and marketing channels. The extensive set of firms' characteristics we can control for assuages, to some extent, these concerns.

Mechanisms: Worker Absence and Transport. In the firm interviews we asked, on a week-by-week basis for the period covering January and February 2008, (i) how many workers were absent, and (ii) whether the firm suffered transportation problems. We now use these measures to provide suggestive evidence on the relevance of these two mechanisms.

Before describing the results, it is worth pointing out certain limitations of this exercise. The retrospective nature of the survey might introduce measurement error in the form of imperfect recall or even bias. For example, respondents may be more likely to recall worker absence as a problem if they were located in the violence region and have more salient memories of worrying about worker absenteeism. Furthermore, the extent of measurement error could be different between reported worker absence and transportation problems.

Although we cannot provide any evidence to assuage such concerns, the interviews

\footnotetext{
${ }^{13}$ Although firms that export directly suffer lower reductions in exports than firms exporting through the auctions, the estimates imply an overall reduction in exports for both types of firms. In a sample of wellestablished relationships, Macchiavello and Morjaria (2015) estimate a 17\% drop in exports in the average relationship. Section 3.5 explores how global buyers in direct relationships react to the shortfall.
} 
we conducted in person left us with reassuring impressions. The events we asked about took place six months before the survey but were still very salient to the respondents. Responses on transportation difficulties appear to correlate well across respondents within narrowly defined localities, as expected. With respect to workers' absence, we asked respondents to check payroll records 14

A second caveat to this analysis is that both the percentage of workers absent and, possibly to a lesser extent, transportation problems experienced by the firm are likely to be, at least in part, the result of an endogenous response by firms to the violence and insecurity.

Notwithstanding these caveats, Appendix Table [C8] reports the results. Specifications are analogous to those in previous tables, but note that the regressions are estimated on the sample of interviewed firms only and the unit of observation is at the firm-week level since the survey variables were asked on weekly basis. Column (1) simply recovers an average reduced form effect of the violence at the week level. The estimated coefficient is similar to the estimates obtained in previous specifications. Columns (2) and (3) show that the time-varying self-reported measures of worker losses and transportation problems correlate with lower exports. In all cases, estimated coefficients are negative, economically sizeable, and statistically significant at conventional level.

Column (4) considers the three variables together to quantify the relative importance of workers' absence, transportation problems, and the general situation related to the violence in the location of the firm. All estimated coefficients drop by about half and are no longer statistically significant at conventional level. The results thus suggest that it is difficult to statistically attribute the overall effects on exports to specific channels. In the survey, however, only $50 \%$ of firms in the conflict areas report transportation difficulties, while

\footnotetext{
${ }^{14}$ We could not access the payroll records directly and, unfortunately, we did not take note during the interviews about whether the respondent consulted payroll records. Looking at the survey, some respondents provided precise numbers for workers' absence while other responses do suggest that the interviewee used focal categories, suggesting measurement error. Whether the measurement error is exacerbated by recall bias would be an open question.
} 
almost $90 \%$ report worker absenteeism due to the violence. To gauge the extent to which worker absence affected exports, column (5) restricts the sample in the violence regions to those firms that did not experience transportation problems. Interestingly, the point estimate is indistinguishable from the one estimated using the full survey sample in column (2). Although the change in sample warrants caution in interpreting the results, the evidence is consistent with worker losses having been a very important mechanisms through which the violence affected exports.

Quantifying Losses During the Violence. We now attempt to quantify firms' losses during the violence. The model in the Appendix provides guidance on how firm-specific reduced form estimates of the effects of the violence on production, $\Delta^{v}$, can be combined with knowledge of the firm's revenues per worker during normal times, $R^{*}$, and estimates of key underlying parameters to provide a back-of-the-envelope calculation of the effects of the violence on firms' profits 15

Weekly revenues per worker $R^{*}$ in normal times are easily computed, for each firm, by dividing a firm's export revenues in normal times, proxied by the median weekly revenues during the 10 weeks control period that preceded the violence (which are available from trade transaction records), by the number of workers employed by the firm (which is available, for the same period, from the survey). There are two key parameters to be estimated: the elasticity of output to the number of workers $(\eta)$ and the elasticity of workers effort costs to hour worked $(\gamma)$. We assume that these are identical across firms. The share of wage costs in revenues is equal to $\psi=\frac{1}{1+\gamma}$. Information collected in the survey suggests $\psi \simeq 0.2$ for a typical firm, implying $\gamma \simeq 4$. Note that weekly earnings per worker in normal times are equal to $y^{*}=\frac{1}{\gamma+1} R^{*}$. With $\gamma=4$, this gives $\widehat{y}^{*} \simeq 1,250$ Kenyan shillings for workers at the

\footnotetext{
${ }^{15}$ In the survey we also tried to elicit revenue losses and increases in costs, but the reported figures appear to be noisy. Besides sources of measurement error described above, a concern is that some respondents might have inflated losses to influence the business association (with whom we would have shared a report on our findings) to lobby the government for compensation and additional support.
} 
median firm (or 14 Euro at pre-violence exchange rates) 16

With knowledge of $\gamma, \eta$ can be recovered from a regression analogue to the specification in Table [4, with the log of the share of retained workers replacing the share of missing workers. Unreported results reveal an estimated $\widehat{\eta}=0.56$ when $\gamma=4$.

Finally, the reduced form effect of the violence on production $\Delta^{v}$ is given by the firmlevel difference-in-difference estimates computed in Table [2, which corresponds to equation (1). Both the reduced form effect of the violence on production, $\Delta^{v}$, and the revenues per worker in normal times, $R^{*}$, are available for each firm separately, the model can be calibrated for each firm. By comparing the share of retained workers reported in the survey with the corresponding estimates from the model calibration, it is possible to further validate the consistency of the model with the data. Results show a 0.73 correlation between the two variables, which is statistically significant at the $1 \%$ level.

Results for the median firm (out of the 37 surveyed in the conflict regions with complete information) are as follows. The drop in production was 56\%. Prices in export markets were not affected by the violence but the Kenyan shilling depreciated by about $10 \%$. The calibration reveals that labor costs in Kenyan shillings increased by $83 \%$ on average but, given the low share of the wage bill in total costs, this translates into a $19 \%$ increase in costs ${ }^{17}$ The median firm would thus have made losses during the violence unless operating profit margins were at least $22 \%$, quite a large number. The estimates thus suggest that the median firm in the violence region likely operated at a loss during the violence.

\footnotetext{
${ }^{16}$ This estimate nicely matches prevailing wage rates in the flower industry at the time of the survey. These were (about) 200 Kenyan shillings per day immediately before the violence, implying weekly earning of around 1,200 Kenyan shillings. For this reason, we take $\gamma=4$ as our preferred estimate. Results are robust using alternative choices of $\psi$ in the range $\psi \in[0.1,0.25]$.

${ }^{17}$ The figure includes both the wages paid for the extra hours worked at the farm for the remaining workers as well as costs incurred to get workers to come to work but does not include other fixed costs (e.g., hiring of extra security). The interviews, however, revealed that those costs were small.
} 


\subsection{Demand-Side Reaction to the Violence}

The violence was thus a large, negative, supply shock to the firms that were affected. Given this negative supply shock, how did the demand side of the market adjust?

Despite the large shock in Kenya, prices at the auction markets in the Netherlands, which consolidate demand and supply across the globe, were not hugely affected by the violence. At the time of the violence Kenya accounted for about $10 \%$ of the world's exports of flowers. The violence hit half of Kenya's industry, reducing exports by about 30\%. This implies that the violence caused a relatively small drop in the aggregate supply at the auctions. We thus focus on the response of global buyers sourcing through direct relationships. These buyers suffered an average reduction in deliveries of about 17\% (see Macchiavello and Morjaria (2015)). We now consider their ability to cope with this shock by shifting sourcing to other suppliers in Kenya and abroad that were not directly affected by the violence.

Sourcing from No-Conflict Areas in Kenya. For a global buyer regularly sourcing flowers from firms hit by the violence in Kenya, a first response margin would have been to try to increase sourcing from Kenyan suppliers not directly affected by the violence. Besides its intrinsic interest, exploring this channel also allows us to discuss potential spillover across regions. Table 2 column (1), and Table 3 Panel $\mathrm{C}$ document that on average firms in the conflict areas did not export more flowers relative to prior seasons and prior years. This suggests that spillovers, if any, do not pose a severe threat to the identification of the reduced form average treatment effect of the violence. The average finding, however, could be hiding two opposing effects. First there might be negative spillovers on firms due to a countrywide effect of the insecurity. Second, there might be a positive spillover if some firms in the no-conflict area benefited from additional demand for their flowers.

To explore this hypothesis, we focus on buyer-firm relationships in which the global buyer sourced from firms in both the conflict and no-conflict area. We test for whether 
buyers who were sourcing from exporters located in the conflict area were able to source additional flowers from firms in the no-conflict area. Table 6 presents the results focusing on buyer-seller pairs that had relationships before the onset of the violence. Increases along the intensive margin of trade provides the best path to find evidence of positive spillover since the data reveal that none of the 64 buyers that exclusively sourced from the conflict region before the violence was able to start sourcing from the no-conflict region during the shock. In total, 48 buyers were sourcing in both regions before the violence.

The table explores both specifications with firm and buyer fixed effects (columns (1) and (3)), as well as specifications in which we condition for buyer-seller pair fixed effects (columns (2) and (4)). Columns (1) and (2) consider a continuous measure of exposure, defined as the share of flowers imported from Kenya that the buyer sourced in the conflict region. Columns (3) and (4) instead consider a simple indicator for whether the buyer was sourcing any flower at all from the violence region. All specifications include day-ofyear, day-of-week and winter fixed effects. Across the board, we find that buyers that were sourcing from the conflict region were not able to shift their sourcing to exporters located in the no-conflict region. Although the estimated coefficient is positive, it is small and far from being statistically significant in all the specifications.

Sourcing from Ethiopia. Global buyers sourcing in Kenya at the time of the violence had a second potential margin of adjustment: increase imports from other origins. The closest substitutes for Kenyan flowers is nearby Ethiopia, a country with a burgeoning flower export industry of its own and that has consciously supported the development of the sector through an active industrial policy. Using detailed custom records from Ethiopia, we analyze whether global buyers that were exposed to the violence in Kenya were able to increase sourcing from the country. Besides its usefulness for understanding buyers' response, the analysis also has potentially important welfare implications. Globally, the negative welfare 
impacts of the violence may well be less if other countries are able to compensate for reduced Kenyan exports by exporting more.

Table 7 reports the results. Among the 99 global buyers sourcing from Ethiopia just before the violence, only 16 were also sourcing from Kenya and 9 specifically from the regions affected by the violence $\sqrt{18}$ We consider both separately. Note that, consistent with the evidence from Kenya in Table [6], none of the buyers sourcing flowers in Kenya but not Ethiopia just before the violence was able to start sourcing in Ethiopia.

The empirical specifications are similar to those in Table [6], and consider both the continuous and discrete definition of exposure to Kenya in general, and to the regions with the violence in particular. For simplicity, we focus on specifications that include buyer-seller pair fixed effects, but results are qualitatively identical when considering the two sets of fixed effects separately. Across the board, we find that no evidence that global buyers were able to relocate supplies from Kenya to Ethiopia on short notice 19

Medium-Term Effects of the Violence. In sum, the available evidence suggests that, to a large extent, global buyers were unable to easily shift sourcing to respond to supplychain disruptions caused by the violence. This evidence is consistent with Macchiavello and Morjaria (2015), which establish that exporters value maintaining a reputation for reliable deliveries to existing buyers and that it takes time to establish new relationships.

The violence might have had additional medium-term impacts. In the flower industry, contracts with direct buyers are renegotiated at the end of the summer. Within firms, relationships that were not prioritized by the firm during the violence are more likely to break down and not survive to the next season relative to relationships that were prioritized

\footnotetext{
${ }^{18}$ These figures suggests that relatively few buyers diversify their sourcing origins in the industry. Similar patterns are observed in the Ethiopian floriculture industry, see Antić et al. (2021) for additional details on the Ethiopian context.

${ }^{19}$ The estimated coefficients using the continuous definition of exposure appear large (although indistinguishable from zero) but simply because the average exposure measure is low. They thus imply very small economic magnitudes.
} 
by the firm. From the firm perspective, however, the overall impact was modest. This is likely due to the possibility of selling to the auctions and forming new relationships. In particular, we check survival rates in the industry one year and two years after the violence. We consider firms located in the conflict region and those located in the no-conflict region. We further split the groups between firms that, at the time of the violence, were predominantly selling through direct relationships versus those that predominantly sold to the auctions. We find no statistically significant difference in survival rate and export performance across the four groups two years after the violence.

Mitigating Supply-Chain Risk: Evidence from Kenya's 2013 Election. The evidence thus suggests that it is difficult for global buyers to cope with supply-chain disruptions when they occur. If this is the case, we might expect firms to take precautionary measures when the risk of supply-chain disruptions increase.

Although the industry fully recovered from the short-lived violence in 2008 , the violence might have cast a long shadow into the future. Specifically, it is possible that the violence changed firms' expectations of post-election violence. We analyze whether Kenyan flower firms (and their buyers) changed the schedule and volume of exports in possible anticipation of violence around the next presidential elections that took place on March 4, 2013. This would also document whether buyers and firms expected violence or disruptions.

We begin by estimating a countrywide difference-in-differences specification similar to columns (1) and (2) in Table 2 but for the entire country. We define the potential period of violence as the period after March 4, 2013. Figure 3 visually suggests that there is a change in behavior of exporters taking place, and columns (1), (3) and (5) of Table 8 show that these changes are statistically significant.

We also investigated whether these expectations of violence reacted to the patterns of violence in 2008 - that is, whether firms located in areas in which there was violence in 
2008 changed their behavior. We do not find any evidence of a location-specific effect. This may be explained by the fact that the ethnic compositions of the two coalitions changed across the two elections, so the fault lines would not have been the same as in 2008.

Because firms have a much stronger incentive to maintain relationships we observed differences in exporting behavior by marketing channel in 2008 , we also analyze whether such differences can be observed in 2013. Panel B of Figure 3 shows the share of a firm's exports going to direct buyers versus the auction. We find that firms did prioritize exports to direct buyers in the days before the election, while there is a visible dip in the share of exports to firms just after the election.

While this pattern is precisely measured (see columns (2), (4) and (6) of Table 8), the overall effect is statistically significant but relatively small. We conducted phone interviews with a few exporters before the election to gather qualitative information about their behavior. The phone interviews suggest that many firms did not perceive the risk of a repeat of the 2008 post-election violence to be particularly high in 2013. Those who did reported that flowers are perishable and have a limited shelf life, and thus adjustments in the schedule of shipments were limited and restricted to buyers with adequate facilities to store flowers.

\section{Conclusions}

This paper combined detailed administrative records on production, an original firm survey, and several other data sources, to understand how post-electoral violence in 2008 affected the Kenyan flower industry.

On the supply side, the results show that the violence induced a large negative shock. After controlling for firm-specific seasonality patterns and growth, weekly export volumes of firms in the affected regions dropped, on average, by $56 \%$ relative to what would have happened had the violence not occurred. Large firms and firms with stable contractual 
relationships in export markets registered smaller percentage losses in production. These firms also reported smaller percentages of workers missing during the time of the violence.

On the demand side, global buyers were not able to compensate the reduction in deliveries by increasing sourcing from either Kenyan exporters located in areas not directly affected by the violence nor from neighboring Ethiopian suppliers. Consistent with difficulties in insuring against supply-chain risk disruptions caused by electoral violence, exporters and buyers in direct contractual relationships mitigated risk by ramping up shipments just before the subsequent presidential election.

Taken together, the results have implications for policy makers and business executives alike. From a policy perspective, the findings from this study are relevant to countries interested in fostering nontraditional agricultural value chains. For example, the success of floriculture in Kenya has led several Sub-Saharan countries, most notably Ethiopia, but also Tanzania, Uganda, Zambia, and Rwanda among others, to promote the development of the industry. Our results suggest that incentives associated with stable relationships in nontraditional agriculture encouraged firms to quickly respond to the violence. 20 Stable relationships might be associated with higher exporters' margins (see Cajal-Grossi et al. (2019) ) but can also lead to foreclosure and less competitive conduct (see, e.g., Boehm and Sonntag (2020)). While this study does not provide a comprehensive evaluation of the social benefits of such export arrangements, it provides a novel rationale for why policy makers in countries prone to instability might promote the adoption of such arrangements among exporters ${ }^{21}$ The results also have implications for business executives organizing sourcing from politically unstable environments. In particular, the same market frictions, such as

\footnotetext{
${ }^{20}$ This suggests that the negative effects of the violence might be even larger in traditional agriculture value chains in which domestic traders and processors market the fresh produce of smaller farmers, often for the local market.

${ }^{21}$ From a broader perspective, Hernandez (2015) finds that the growth of the flower sector was associated with lower rates of unorganized violent crime but no change in guerrilla warfare in Colombia. In the African context, the development of the flower industry has created job opportunities in rural areas but might have exacerbated tensions over land and water.
} 
search costs and limited contract enforcement, that make stable relationships with suppliers valuable can also hinder global buyers' ability to cope with disruptions by swiftly shifting sourcing to alternative suppliers. Diversifying sourcing origins and planning precautionary measures when risks of disruptions increase become essential tools of the trade.

\section{References}

Alesina, Alberto, Sule Özler, Nouriel Roubini, and Phillip Swagel, "Political Instability and Economic Growth," Journal of Economic Growth, 1996, 1 (2), 189-211.

Amodio, Francesco and Michele Di Maio, "Making Do with What You Have: Conflict, Input Misallocation, and Firm Performance," The Economic Journal, 2017, 128 (615), $2559-2612$.

_ , Leonardo Baccini, and Michele Di Maio, "Security, Trade, and Political Violence," Technical Report IZA Discussion Papers No. 10819, Institute of Labour Economics (IZA), Bonn 2017.

Antić, Nemanja, Ameet Morjaria, and Miguel Talamas, "Building Relationships in Ethiopia's Flower Exports," Working Paper, Kellogg School of Management 2021.

Barrot, Jean-Noël and Julien Sauvagnat, "Input Specificity and the Propagation of Idiosyncratic Shocks in Production Networks," The Quarterly Journal of Economics, 2016, 131 (3), 1543-1592.

Bates, Robert, Prosperity and Violence: The Political Economy of Development, New York, USA: W. W. Norton \& Company, 2001.

- , When Things Fell Apart: State Failure in Late-Century Africa, New York, USA: Cambridge University Press, 2008.

Besley, Timothy and Torsten Persson, "The Incidence of Civil War: Theory and Evidence," 2008. mimeo, LSE and IIES, Stockholm.

Blattman, Christopher and Edward Miguel, "Civil War," Journal of Economic Literature, 2010, 48 (1), 3-57. 
Blouin, Arthur and Rocco Macchiavello, "Strategic Default in the International Coffee Market," The Quarterly Journal of Economics, 2019, 134 (2), 895-951.

Blumenstock, Joshua, Tarek Ghani, Sylvan Herskowitz, Ethan B. Kapstein, Thomas Scherer, and Ott Toomet, "Insecurity and Industrial Organisation: Evidence from Afghanistan," Policy Research Working Paper No. 8301, World Bank, Washington, DC 2018. License: CC BY 3.0 IGO.

Boehm, Johannes and Jan Sonntag, "Vertical Integration and Foreclosure: Evidence from Production Network Data," 2020.

Burgess, Robin, Remi Jedwab, Edward Miguel, Ameet Morjaria, and Gerard Padró i Miquel, "The Value of Democracy: Evidence from Road Building in Kenya," American Economic Review, 2015, 105 (6), 1817-1851.

Cajal-Grossi, Julia, Rocco Macchiavello, and Guillermo Noguera, "International Buyers' Sourcing and Suppliers' Markups in Bangladeshi Garments," 2019.

Cameron, Colin A., Jonah B. Gelbach, and Douglas L. Miller, "Robust Inference with Multi-way Clustering," Journal of Business 83 Economic Statistics, 2011, 29 (2), 238-249.

Carvalho, Vasco M., Makoto Nirei, Yukiko Saito, and Alireza Tahbaz-Salehi, "Supply chain disruptions: Evidence from the great east japan earthquake," Quarterly Journal of Economics, 2021, (forthcoming).

Catholic Justice and Peace Commission, An Investigative Report on Post Election Violence in Kenya 2008.

Collier, Paul, The Bottom Billion: Why the Poorest Countries are Failing and What Can Be Done About It, New York: Oxford University Press, 2007.

- and Anke Hoeffler, "On Economic Causes of Civil War," Oxford Economic Papers, $1998,50,4$.

_ and Marguerite Duponchel, "The Economic Legacy of Civil War: Firm Level Evidence from Sierra Leone," Journal of Conflict Resolution, 2013, 57 (1), 65-88. 
Dercon, Stefan and Roxana Gutiérrez-Romero, "Triggers and Characteristics of the 2007 Kenyan Electoral Violence," World Development, 2012, 40 (4), 731-744. ISSN 0305$750 \mathrm{X}$.

Dube, Oeindrila and Juan F. Vargas, "Commodity Price Shocks and Civil Conflict: Evidence From Colombia," The Review of Economic Studies, 2013, 80 (4 (285)), 13841421.

Dupas, Pascaline and Jonathan Robinson, "The (Hidden) Costs of Political Instability: Evidence from Kenya's 2007 Election Crisis," Journal of Development Economics, 2012, 99 (2), 314-329. ISSN 0304-3878.

Gibson, Clark C. and James D. Long, "The Presidential and Parliamentary Elections in Kenya, December 2007," Electoral Studies, 2009, pp. 1-6.

Glick, Reuven and Alan M. Taylor, "Collateral Damage: Trade Disruption and the Economic Impact of War," Review of Economics and Statistics, 2010, 92 (1), 102-127.

Guidolin, Massimo and Eliana La Ferrara, "Diamonds Are Forever, Wars Are Not: Is Conflict Bad for Private Firms?," American Economic Review, 2007, 97 (5), 1978-1993.

Hernandez, Sarah, "Guns N'Roses: The Impact of Female Employment Opportunities on Violence in Colombia." PhD dissertation, Thesis: PhD, Massachusetts Institute of Technology, Department of Economics 2015.

Hjort, Jonas, "Ethnic Divisions and Production in Firms," Quarterly Journal of Economics, 2014, 129 (4), 1899-1946.

Independent Review Commission, Report of the Independent Review Commission on the General Elections held in Kenya on 27th December 20072008.

Kenya National Commission on Human Rights, "On the Brink of the Precipice: A Human Rights Account of Kenya's Post-2007 Election Violence," 2008. Nairobi, Kenya.

Kenya Red Cross Society, "Information Bulletins (01 January 2008 - 04 March 2008)," 2008. Last accessed on 22 September 2008.

Klapper, Leora, Christine Richmond, and Trang Tran, "Civil Conflict and Firm Performance : Evidence from Cote d'Ivoire," Policy Research Working Paper No. WPS 6640, World Bank, Washington, DC 2013. 
Korovkin, Vasily and Alexey Makarin, "Trading with the Enemy: The Impact of Conflict on Trade in Non-Conflict Areas," 2019. Working Paper.

Macchiavello, Rocco and Ameet Morjaria, "The Value of Relationships: Evidence from a Supply Shock to Kenyan Rose Exports," American Economic Review, September 2015, $105(9)$.

Martin, Philippe, Thierry Mayer, and Mathias Thoenig, "Civil Wars and International Trade," Journal of the European Economic Association, April-May 2008, 6 (2-3), $541-550$.

Montoya, Eduardo, "Violence and Economic Disruption: Firm-level Evidence from Mexico," 2016. Technical report, Working Paper.

Morjaria, Ameet, "Democracy and the Environment in Kenya," Working Paper, Kellogg School of Management 2018.

Rodrik, Dani, "Growth Strategies," in P. Aghion and S. Durlauf, eds., Handbook of Economic Growth, Vol. 1, Elsevier, 2005, pp. 967-1014.

Rozo, Sandra V., "Is Murder Bad for Business? Evidence from Colombia," The Review of Economics and Statistics, 2018, 100 (5), 769-782.

Straus, Scott and Charlie Taylor, "Democratization and Electoral Violence in SubSaharan Africa, 1990-2007," 2009. APSA Toronto Meeting Paper. 


\section{Figures}

\section{Figure 1: Elections and Violence in Sub-Saharan Africa, 1990-2018}

Panel A: Violence during an election year

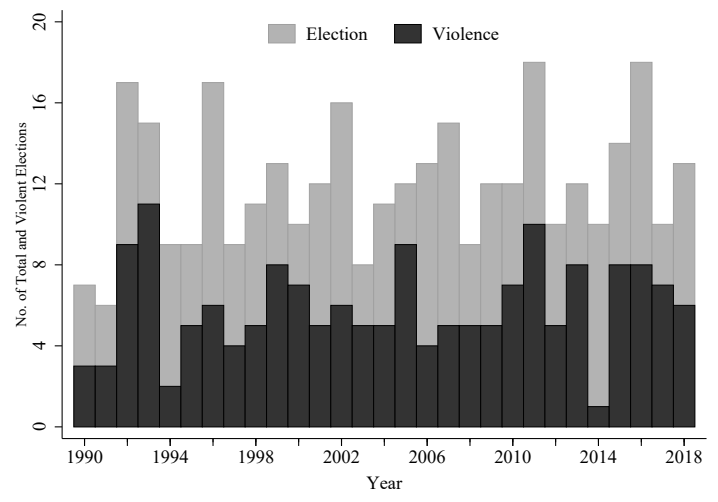

Panel B: Violence post-election

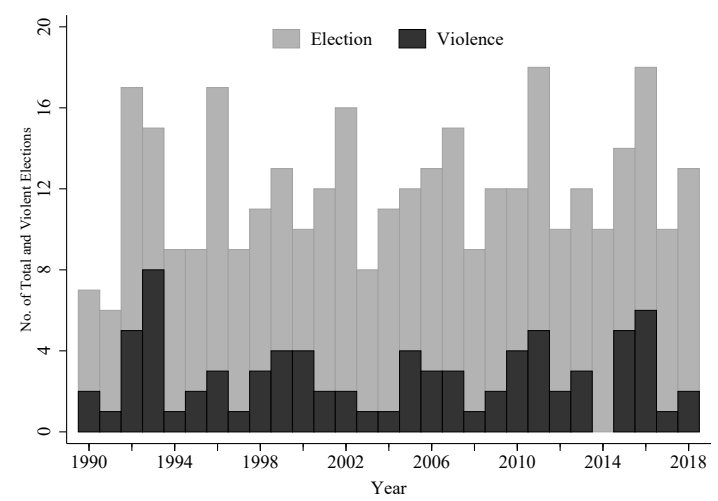

Note: The light gray histogram represents the total number of elections across Sub-Saharan Africa in a given year. The black histogram overlaid on the gray, represents the total number of elections which encountered violence. Calendar year is represented on the x-axis, and the y-axis shows the number of total and violent elections. The figure highlights the frequency of elections in Africa that were associated with violent episodes at any time (Panel A) and post-election (Panel B) within the calendar year corresponding to the election. Data on elections with and without violence were compiled and calculated from the universe of all country-specific Human Rights Reports published by the U.S. Department of State. A review of available sources and news articles reveals that of the 14 presidential, parliamentary, or legislative elections held in 2019,8 saw violence before, during, or after the vote. Appendix D provides additional details. 


\section{Figure 2: Effect of Violence on Export Volumes, Short-Run}

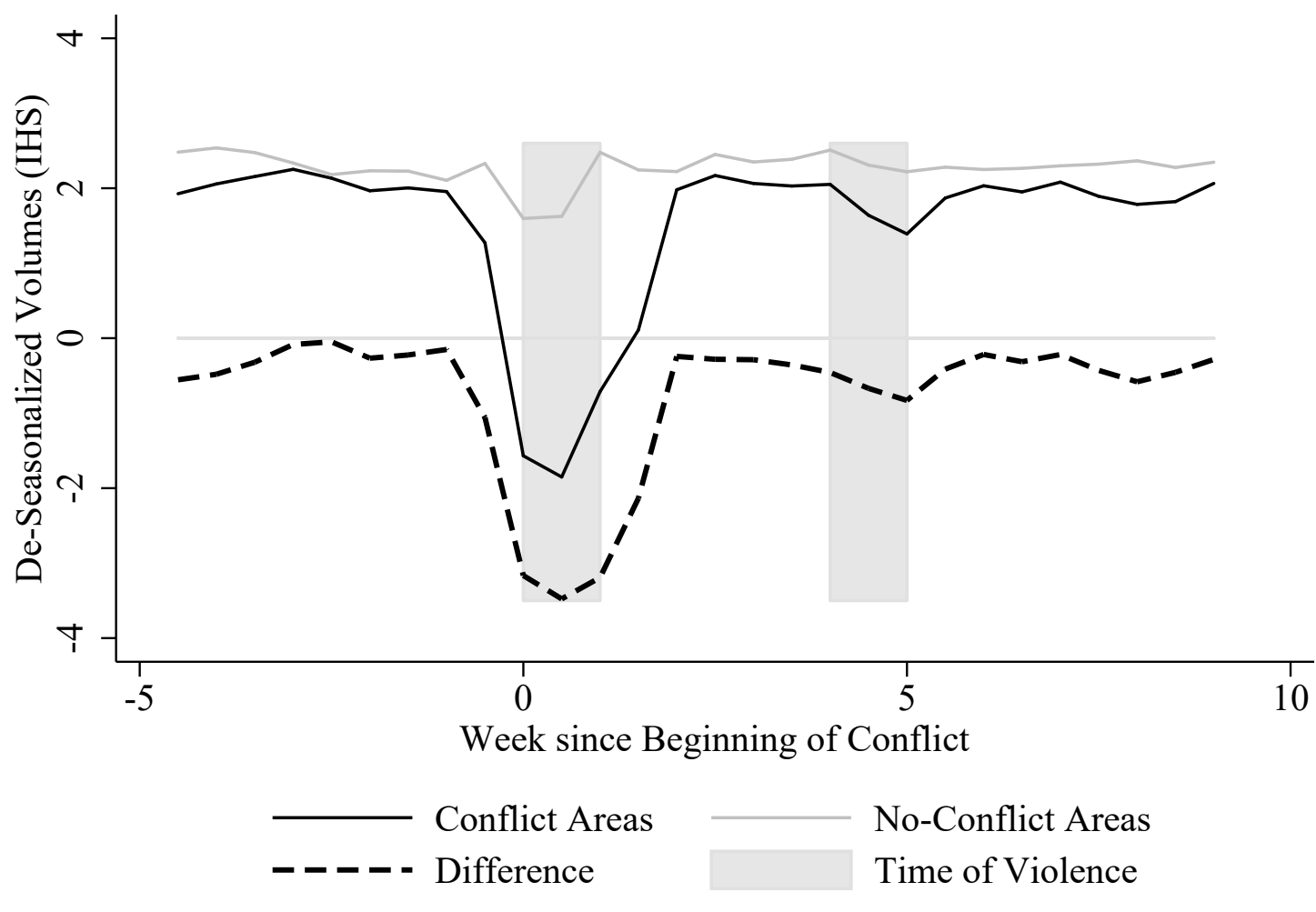

Note: The figure displays the smoothed median biweekly residuals from a regression of export weights (kgs, inverse hyperbolic sine transformation) on the following fixed effects: firm, day of week, and day of year and winter with violence location, and presenting residuals separately for the conflict and no-conflict areas (Table [3, column 4). Smoothing is through simple moving average. The shaded area indicates times of violence. Conflict areas are as defined as in Appendix Table [C1]. 


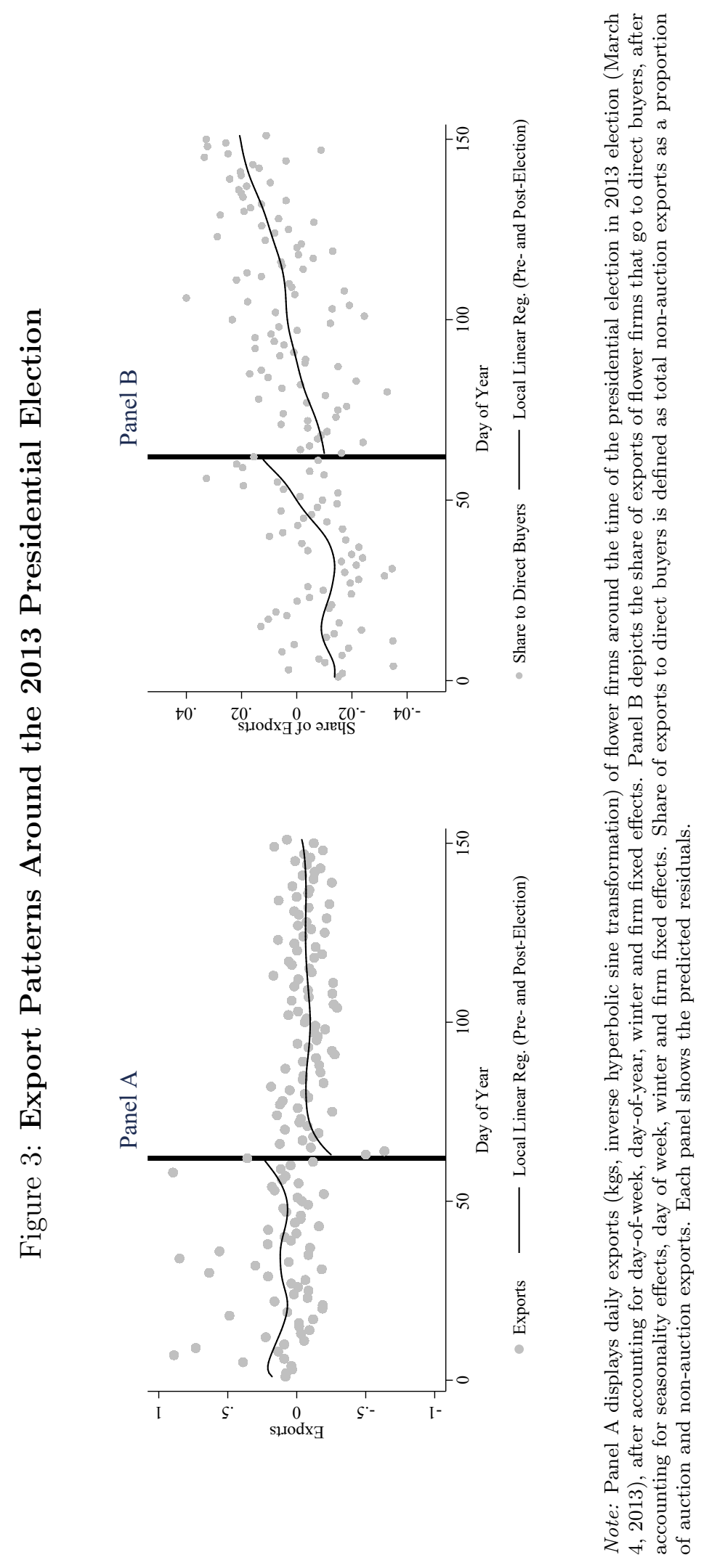




\section{Table 1: Descriptive Statistics}

\begin{tabular}{|c|c|c|c|c|c|}
\hline \multicolumn{6}{|c|}{ Panel A: Firms in Areas with and without Violence, Administrative Records } \\
\hline \multirow[b]{2}{*}{ Variable } & \multicolumn{2}{|c|}{ No violence } & \multicolumn{2}{|c|}{ Violence } & \multirow[b]{2}{*}{ P-value } \\
\hline & Mean & SE & Mean & $\mathrm{SE}$ & \\
\hline Export, Jan-Feb 2007 (kg '000) & 11.54 & $(0.20)$ & 10.95 & $(0.28)$ & 0.10 \\
\hline Small & 0.42 & $(0.07)$ & 0.47 & $(0.06)$ & 0.64 \\
\hline Foreign Owner & 0.32 & $(0.06)$ & 0.42 & $(0.06)$ & 0.22 \\
\hline Indian Owner & 0.21 & $(0.05)$ & 0.21 & $(0.05)$ & 0.98 \\
\hline Kenyan Owner & 0.40 & $(0.07)$ & 0.30 & $(0.06)$ & 0.25 \\
\hline Politically Connected Firm & 0.28 & $(0.06)$ & 0.15 & $(0.04)$ & $0.08^{*}$ \\
\hline Exports to Auctions & 0.40 & $(0.07)$ & 0.26 & $(0.06)$ & $0.10^{*}$ \\
\hline Production in Roses & 0.56 & $(0.07)$ & 0.53 & $(0.06)$ & 0.79 \\
\hline \multicolumn{6}{|c|}{ Panel B: Firms in Areas with and without Violence, Survey Data } \\
\hline & \multicolumn{2}{|c|}{ No violence } & \multicolumn{2}{|c|}{ Violence } & \\
\hline Variable & Mean & $\mathrm{SE}$ & Mean & SE & P-value \\
\hline Number of Workers Jan 2008 & 521.89 & $(112.59)$ & 441.13 & $(45.34)$ & 0.44 \\
\hline Female Workers $(\%)$ & 61.42 & $(2.18)$ & 64.39 & $(2.68)$ & 0.42 \\
\hline Temporary Workers (\%) & 18.56 & $(4.98)$ & 23.78 & $(4.37)$ & 0.45 \\
\hline Workers with Primary Education (\%) & 90.40 & $(1.57)$ & 91.21 & $(1.46)$ & 0.71 \\
\hline Workers Housed & 0.48 & $(0.10)$ & 0.30 & $(0.07)$ & 0.13 \\
\hline Entry Year & 1997 & $(1.06)$ & 1999 & $(0.72)$ & $0.03^{* *}$ \\
\hline Association Member & 0.67 & $(0.09)$ & 0.49 & $(0.08)$ & 0.15 \\
\hline Certification & 0.81 & $(0.08)$ & 0.69 & $(0.07)$ & 0.25 \\
\hline Number of Insulated Trucks & 1.42 & $(0.24)$ & 1.05 & $(0.24)$ & 0.29 \\
\hline Sold to Direct Buyers (\%) & 50.36 & $(8.73)$ & 38.54 & (6.73) & 0.28 \\
\hline Workers at Risk (\%) & 12.38 & $(2.73)$ & 32.57 & $(4.89)$ & $0.00^{* * *}$ \\
\hline Affected Operations & 0.37 & $(0.09)$ & 0.87 & $(0.05)$ & $0.00^{* * *}$ \\
\hline Experienced Worker Absence & 0.23 & $(0.08)$ & 0.87 & $(0.05)$ & $0.00^{* * *}$ \\
\hline Workers Lost (\%) & 4.15 & $(2.72)$ & 49.33 & $(5.75)$ & $0.00^{* * *}$ \\
\hline Production Loss because of Worker Absence & 0.26 & $(0.17)$ & 2.35 & $(0.20)$ & $0.00^{* * *}$ \\
\hline Transportation Problems & 0.26 & $(0.09)$ & 0.64 & $(0.07)$ & $0.00^{* * *}$ \\
\hline Hire Extra Security & 0.08 & $(0.06)$ & 0.38 & $(0.08)$ & $0.01^{* * *}$ \\
\hline \multicolumn{6}{|c|}{$\begin{array}{c}\text { Panel C: Surveyed vs. Non-Surveyed Firms, Administrative Records } \\
\end{array}$} \\
\hline & \multicolumn{2}{|c|}{ No violence } & \multicolumn{2}{|c|}{ Violence } & \\
\hline Variable & Mean & SE & Mean & $\mathrm{SE}$ & P-value \\
\hline Export, Jan-Feb 2007, in kg '000 & 10.82 & $(0.31)$ & 11.50 & $(0.21)$ & $0.06^{*}$ \\
\hline Violence Region & 0.40 & $(0.07)$ & 0.63 & $(0.06)$ & $0.01^{* *}$ \\
\hline Small & 0.51 & $(0.07)$ & 0.40 & $(0.06)$ & 0.26 \\
\hline Foreign Owner & 0.34 & $(0.07)$ & 0.40 & $(0.06)$ & 0.52 \\
\hline Indian Owner & 0.20 & $(0.06)$ & 0.22 & $(0.05)$ & 0.80 \\
\hline Kenyan Owner & 0.34 & $(0.07)$ & 0.36 & $(0.06)$ & 0.85 \\
\hline Politically Connected Firm & 0.20 & $(0.06)$ & 0.22 & $(0.05)$ & 0.80 \\
\hline Exports to Auctions & 0.38 & $(0.07)$ & 0.28 & $(0.06)$ & 0.27 \\
\hline Production in Roses & 0.45 & $(0.07)$ & 0.61 & $(0.06)$ & $0.08^{*}$ \\
\hline
\end{tabular}

Note: ${ }^{* * *},{ }^{* *}, *$ denote statistical significance at the 1,5 and 10 percent levels, respectively. Panel A tests differences in samplemeans for firms in the regions affected by the violence and firms in regions unaffected by the violence using administrative records only. The sample of firms is the universe of established exporters active in the industry at the time of the violence, after excluding the four largest firms, traders and infrequent exporters. Exports in the first two months of 2007 (in '000 kgs), Production in Roses and Exports to Auctions are computed from custom records. Small, firm ownership (Foreign, Indian and Kenyan) and Politically Connected Firm are all dummy variables. Panel B tests differences in sample-means for firms in the locations affected by the violence and firms in locations unaffected by the violence using information collected through a face-to-face survey designed and conducted by the authors. Workers Housed is a dummy variable taking a value of 1 if the firm offers housing for workers at the premises and 0 otherwise. Entry Year is the year in which the firm starts to export flowers. Association Member is a dummy variable taking a value of 1 if the firm is a member of the Kenya Flower Council and 0 otherwise. Certification is a dummy variable taking a value of 1 if the firm is a participant in any of the standard certification programs during our study period (Fair-Trade, Max Havelaar Switzerland, Milieu Programma Sierteelt, and Kenya Flower Council certification). Workers at Risk is percentage of the workforce that is at risk of violence. We define being at risk as being a member of an ethnic group that was in the opposite alliance from the majority ethnic group of the location from Population Census data. Affected Operations, Experienced Worker Absence, Transportation Problems and Hire Extra Security are all dummy variables capturing margins of firm disruptions due to electoral violence. Production Loss because of Worker Absence is a categorical variable taking values from 0 (not at all) to 4 (severe). Panel C shows that surveyed and non-surveyed firms do not differ for the administrative data available for both samples. Violence Region is a dummy taking a value of 1 if the firm is an locality where electoral violence took place, 0 otherwise. Details on data construction and data source are provided in Appendix D. 


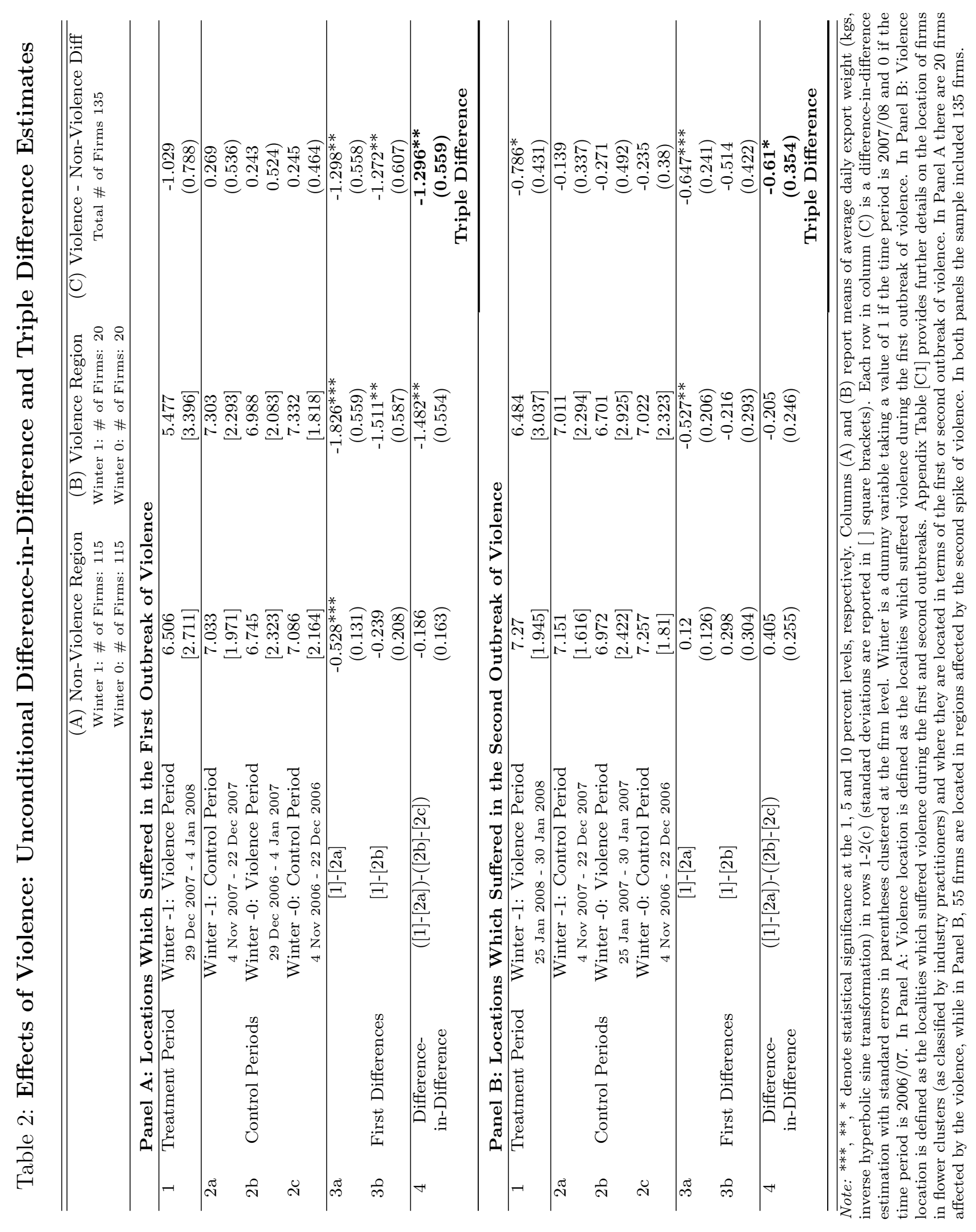




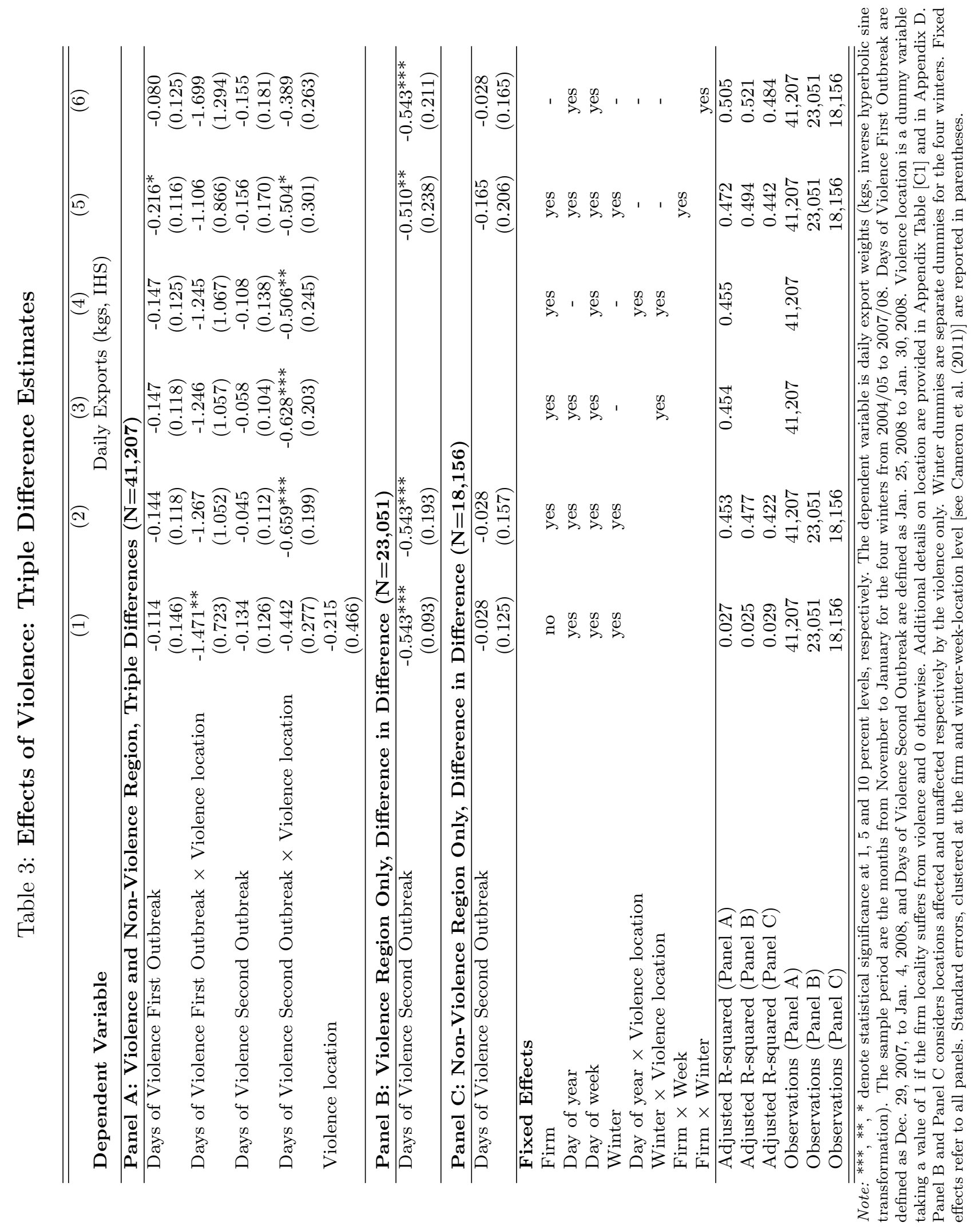




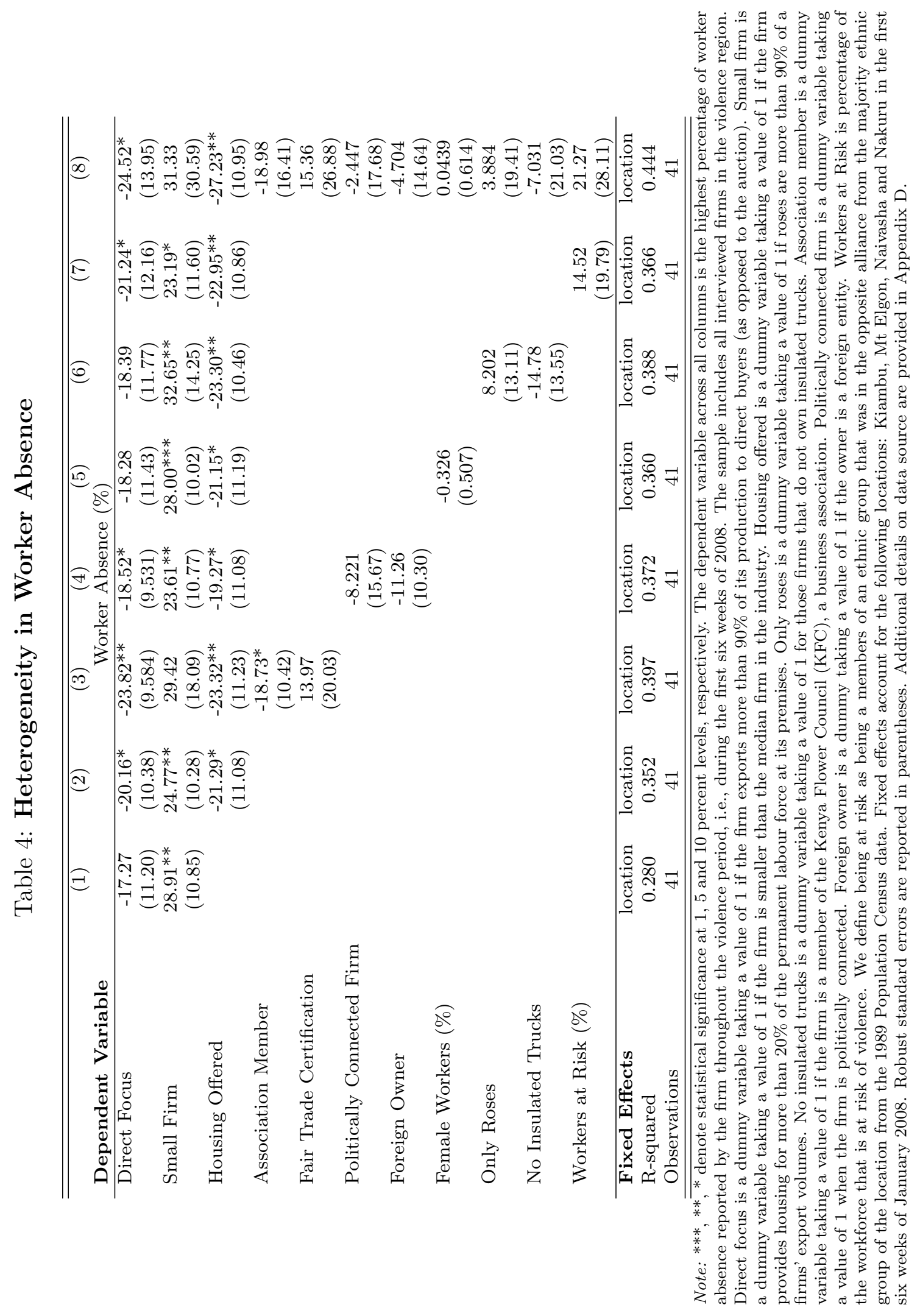




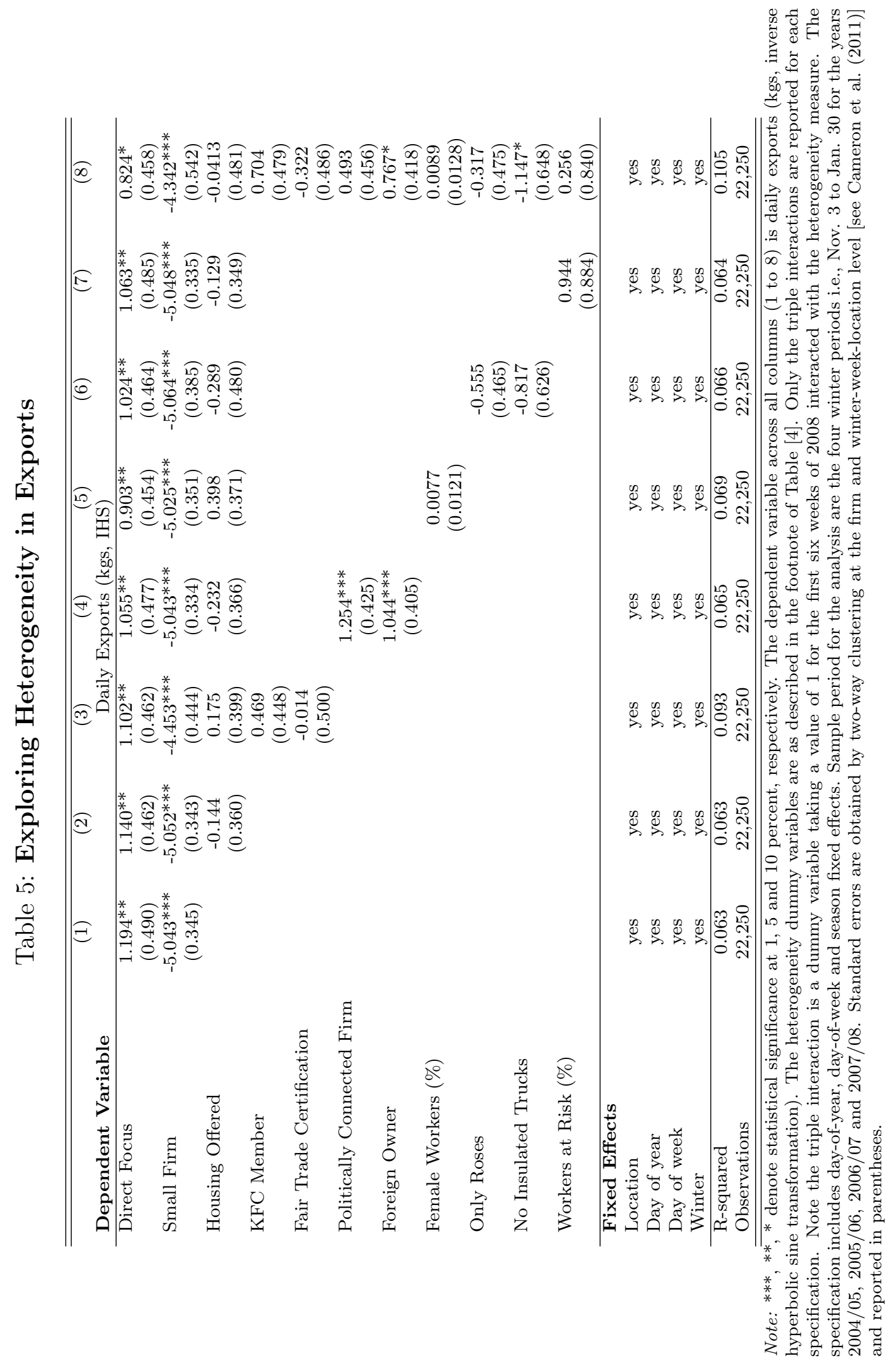




\section{Table 6: Buyer-Driven Spillovers Across Regions within Kenya}

\begin{tabular}{|c|c|c|c|c|}
\hline \multirow[b]{2}{*}{ Dependent Variable } & $(1)$ & $(2)$ & $(3)$ & $(4)$ \\
\hline & \multicolumn{4}{|c|}{ Total Daily Exports (kgs, IHS) in Firm-Buyer pair } \\
\hline Days of Violence & $\begin{array}{l}-0.037 \\
(0.058)\end{array}$ & $\begin{array}{l}-0.037 \\
(0.043)\end{array}$ & $\begin{array}{l}-0.012 \\
(0.055)\end{array}$ & $\begin{array}{l}-0.012 \\
(0.045)\end{array}$ \\
\hline $\begin{array}{l}\text { Days of Violence } \times \text { Proportion Purchased from Violence Location } \\
\text { in the Months Preceding Violence }\end{array}$ & $\begin{array}{c}0.066 \\
(0.174)\end{array}$ & $\begin{array}{c}0.066 \\
(0.131)\end{array}$ & & \\
\hline $\begin{array}{l}\text { Days of Violence } \times \text { Any Purchase from Violence Location } \\
\text { in the Months Preceding Violence }\end{array}$ & & & $\begin{array}{l}-0.012 \\
(0.081)\end{array}$ & $\begin{array}{l}-0.012 \\
(0.067)\end{array}$ \\
\hline \multicolumn{5}{|l|}{ Fixed Effects } \\
\hline Buyer & yes & no & yes & no \\
\hline Firm - Buyer & no & yes & no & yes \\
\hline Day of year & yes & yes & yes & yes \\
\hline Day of week & yes & yes & yes & yes \\
\hline Winter & yes & yes & yes & yes \\
\hline Adjusted R-squared & 0.094 & 0.305 & 0.094 & 0.305 \\
\hline Observations & 218,811 & 218,811 & 218,811 & 218,811 \\
\hline
\end{tabular}

Note: ***,**,* denote statistical significance at 1, 5 and 10 percent, respectively. The dependent variable across all columns ( 1 to 4 ) is total daily exports (kgs, inverse hyperbolic sine transformation) in a firm-buyer relationship. Days of violence is a dummy variable taking a value of 1 if the date in the sample is between and including Dec. 29,2007 to Jan. 4 , 2008 and Jan. 25, 2008 to Jan. 30, 2008; and 0 otherwise. Proportion purchased from violence location in the months preceding violence, is the proportion of flower purchases the buyer of this exporter-buyer pair (i.e. a direct relationship) made from a violence location as a proportion of all of the buyer's purchases in the months prior to the occurrence of violence. Any purchase from violence location in the months preceding violence, is a dummy variable which takes the value of 1 if there are any purchases the buyer in this exporter-buyer pair (i.e. direct relationship) made from any exporter located in a violence location. Violence location are localities which suffered violence during the first or second outbreaks. Appendix Table [C1] provides further details on the location of firms in flower clusters (as classified by industry practitioners) and where they are located in terms of the first or second outbreak of violence. Preceding violence refers to the period Nov. 1, 2007 to Dec. 21, 2007. Sample period for the analysis is Nov. 3 to Jan. 30 for the years 2004 to 2010, i.e. six winters. Standard errors are obtained by two-way clustering [see Cameron et al. (2011)] at buyer and season-week level (columns 1 and 3 ) and buyer-firm relationship and season-week level (columns 2 and 4 ) and reported in parentheses. 
Table 7: Buyer-Driven Spillovers into Ethiopia

\begin{tabular}{|c|c|c|c|c|c|}
\hline \multirow{3}{*}{$\begin{array}{l}\text { Dependent Variable } \\
\text { Days of Violence }\end{array}$} & \multirow{2}{*}{$\begin{array}{c}(1) \\
\text { Total Dai }\end{array}$} & \multirow{2}{*}{$(2)$} & $(3)$ & $(4)$ & \multirow{2}{*}{$\begin{array}{l}(5) \\
\text { uyer pair }\end{array}$} \\
\hline & & & $(\mathrm{kgs}, \mathrm{IH}$ & ) in Firn & \\
\hline & $\begin{array}{l}-0.080 \\
(0.059)\end{array}$ & $\begin{array}{l}-0.082 \\
(0.062)\end{array}$ & $\begin{array}{l}-0.082 \\
(0.062)\end{array}$ & $\begin{array}{l}-0.082 \\
(0.062)\end{array}$ & $\begin{array}{l}-0.082 \\
(0.062)\end{array}$ \\
\hline $\begin{array}{l}\text { Days of Violence } \times \text { Proportion Purchased from Violence Location } \\
\text { in the Months Preceding Violence }\end{array}$ & & $\begin{array}{l}-0.684 \\
(0.593)\end{array}$ & & & \\
\hline $\begin{array}{l}\text { Days of Violence } \times \text { Any Flowers Purchased from Violence Location } \\
\text { in the Months Preceding Violence }\end{array}$ & & & $\begin{array}{l}-0.397^{*} \\
(0.212)\end{array}$ & & \\
\hline $\begin{array}{l}\text { Days of Violence } \times \text { Proportion Purchased from Kenya } \\
\text { in the Months Preceding Violence }\end{array}$ & & & & $\begin{array}{c}0.386 \\
(0.379)\end{array}$ & \\
\hline $\begin{array}{l}\text { Days of Violence } \times \text { Any Flowers Purchased from Kenya } \\
\text { in the Months Preceding Violence }\end{array}$ & & & & & $\begin{array}{c}0.084 \\
(0.253)\end{array}$ \\
\hline \multicolumn{6}{|l|}{ Fixed Effects } \\
\hline Firm & yes & - & - & - & - \\
\hline Firm - Buyer & - & yes & yes & yes & yes \\
\hline Day of year & yes & yes & yes & yes & yes \\
\hline Day of week & yes & yes & yes & yes & yes \\
\hline Winter & yes & yes & yes & yes & yes \\
\hline Adjusted R-squared & 0.199 & 0.360 & 0.360 & 0.360 & 0.360 \\
\hline Observations & 90,478 & 83,997 & 83,997 & 83,997 & 83,997 \\
\hline
\end{tabular}

Note: ***,**,* denote statistical significance at 1, 5 and 10 percent, respectively. The dependent variable across all columns (1 to 4 ) is total daily exports (kgs, inverse hyperbolic sine transformation) in a firm-buyer relationship. Days of violence is dummy variable taking a value of 1 if the date in the sample is between and including Dec. 29,2007 to Jan. 4 , 2008 and Jan. 25, 2008 to Jan. 30, 2008. Proportion purchased from violence location in the months preceding violence, is the proportion of flower purchases the buyer of this exporter-buyer pair (i.e. a direct relationship) made from a violence location in Kenya as a proportion of the buyer's purchases from either Kenya or Ethiopia in the months prior to the occurrence of violence. Any purchase from violence location in the months preceding violence, is a dummy variable which takes the value of 1 if this proportion is bigger than zero. The two variables Proportion purchased from Kenya and Any flowers purchased from Kenya are defined in the same manner, except with reference to exports from Kenya as a whole. Violence location are localities which suffered violence during the first and second outbreaks. Appendix Table [C1] provides further details on the location of firms in flower clusters (as classified by industry practitioners) and where they are located in terms of the first or second outbreak of violence. Preceding violence refers to Nov. 1, 2007 to Dec. 21, 2007. Sample period for the analysis is Nov. 1 to Mar. 9 for the years 2007 to 2010 , i.e. three winters, so that seasonality patterns are estimated with post-violence data. Standard errors obtained through clustering at firm-level (column 1) and firm-buyer relationship level (columns 2-5) and reported in parentheses. 


\section{Table 8: Anticipation Effects in the 2013 Election}

\begin{tabular}{|c|c|c|c|c|c|c|}
\hline Dependent Variable & $\begin{array}{c}(1) \\
\text { Daily } \\
\text { Exports } \\
(\mathrm{kgs}, \mathrm{IHS})\end{array}$ & $\begin{array}{c}(2) \\
\text { Share to } \\
\text { Direct } \\
\text { Buyers }\end{array}$ & $\begin{array}{c}(3) \\
\text { Daily } \\
\text { Exports } \\
\text { (kgs, IHS) }\end{array}$ & $\begin{array}{c}(4) \\
\text { Share to } \\
\text { Direct } \\
\text { Buyers }\end{array}$ & $\begin{array}{c}(5) \\
\text { Daily } \\
\text { Exports } \\
\text { (kgs, IHS) }\end{array}$ & $\begin{array}{c}(6) \\
\text { Share to } \\
\text { Direct } \\
\text { Buyers }\end{array}$ \\
\hline Days before the 2013 election & $\begin{array}{c}0.168^{* *} \\
(0.070)\end{array}$ & $\begin{array}{c}0.032^{* * *} \\
(0.010)\end{array}$ & & & $\begin{array}{c}0.319 * * * \\
(0.072)\end{array}$ & $\begin{array}{c}0.015^{*} \\
(0.009)\end{array}$ \\
\hline Days after the 2013 election & & & $\begin{array}{c}-0.208^{* * *} \\
(0.074)\end{array}$ & $\begin{array}{c}-0.027^{* *} \\
(0.010)\end{array}$ & $\begin{array}{c}-0.307^{* * *} \\
(0.069)\end{array}$ & $\begin{array}{c}-0.015^{*} \\
(0.009)\end{array}$ \\
\hline \multicolumn{7}{|l|}{ Fixed Effects } \\
\hline Firm & yes & yes & yes & yes & yes & yes \\
\hline Day of year & yes & yes & yes & yes & yes & yes \\
\hline Day of week & yes & yes & yes & yes & yes & yes \\
\hline Winter & yes & yes & yes & yes & yes & yes \\
\hline Adjusted R-squared & 0.604 & 0.777 & 0.634 & 0.772 & 0.616 & 0.770 \\
\hline Observations & 46,314 & 18,237 & 66,732 & 26,478 & 113,046 & 44,715 \\
\hline
\end{tabular}

$\overline{\text { Note: }}{ }^{* * *},{ }^{* *},{ }^{*}$ denote statistical significance at 1,5 , and 10 percent, respectively. The dependent variable in columns 1,3 and 5 is daily exports (kgs, inverse hyperbolic sine transformation) and in columns 2, 4 and 6 is the share of exports to direct buyers, defined as total non-auction exports as a proportion of exports to the auction or direct buyers. The 2013 election took place on Mar. 4, 2013. Days before the 2013 election is a dummy variable taking a value of 1 if the date falls between Feb. 24 and Mar. 4, 2013 and 0 otherwise. Days after the 2013 election is a dummy variable taking a value of 1 if the date is including and after Mar. 4 and before Mar. 11, 2013 and 0 otherwise. Sample period in column 1 and 2 are the following periods: Jan. 1-Mar. 3 2011, Jan 1-Mar. 2, 2012 and Jan. 1-Mar. 3, 2013; in column 3 and 4 are the following periods: Mar. 4-May 31, 2011; March 3-May 31, 2012 and Mar. 4-May 31, 2013 and columns 5 and 6 are the days from Jan. 1-May 31 in the years 2011 to 2013. Number of observations reduce from the odd numbered columns to the even numbered columns because the odd numbered columns include zero exports to both auction and non-auction, whereas the even columns are conditional on exporting (since the share to buyers is not defined when no exports were done). Standard errors are clustered at the firm level and reported in parentheses. Additional details are provided in Appendix D. 